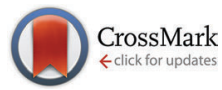

Cite this: Phys. Chem. Chem. Phys., 2016, 18, 13960

Received 7th February 2016 Accepted 19th April 2016

DOI: $10.1039 / c 6 c p 00877 a$

www.rsc.org/pccp

\section{Adsorption of acrolein, propanal, and allyl alcohol on Pd(111): a combined infrared reflection- absorption spectroscopy and temperature programmed desorption study}

\author{
Karl-Heinz Dostert, ${ }^{a}$ Casey P. O'Brien, ${ }^{a}$ Francesca Mirabella, ${ }^{a}$ \\ Francisco Ivars-Barceló ${ }^{a}$ and Swetlana Schauermann ${ }^{\star a b}$
}

\begin{abstract}
Atomistic-level understanding of the interaction of $\alpha, \beta$-unsaturated aldehydes and their derivatives with late transition metals is of fundamental importance for the rational design of new catalytic materials with the desired selectivity towards $\mathrm{C}=\mathrm{C}$ vs. $\mathrm{C}=\mathrm{O}$ bond partial hydrogenation. In this study, we investigate the interaction of acrolein, and its partial hydrogenation products propanal and allyl alcohol, with $\operatorname{Pd}(111)$ as a prototypical system. A combination of infrared reflection-absorption spectroscopy (IRAS) and temperature programmed desorption (TPD) experiments was applied under well-defined ultrahigh vacuum (UHV) conditions to obtain detailed information on the adsorption geometries of acrolein, propanal, and allyl alcohol as a function of coverage. We compare the IR spectra obtained for multilayer coverages, reflecting the molecular structure of unperturbed molecules, with the spectra acquired for sub-monolayer coverages, at which the chemical bonds of the molecules are strongly distorted. Coverage-dependent IR spectra of acrolein on $\mathrm{Pd}(111)$ point to the strong changes in the adsorption geometry with increasing acrolein coverage. Acrolein adsorbs with the $\mathrm{C}=\mathrm{C}$ and $\mathrm{C}=\mathrm{O}$ bonds lying parallel to the surface in the low coverage regime and changes its geometry to a more upright orientation with increasing coverage. TPD studies indicate decomposition of the species adsorbed in the sub-monolayer regime upon heating. Similar strong coverage dependence of the IR spectra were found for propanal and allyl alcohol. For all investigated molecules a detailed assignment of vibrational bands is reported.
\end{abstract}

\section{Introduction}

The atomistic-level understanding of factors governing the selectivity in partial selective hydrogenation of $\alpha, \beta$-unsaturated aldehydes and ketones over transition metal surfaces is of fundamental importance for numerous industrial processes. ${ }^{1}$ The primary hydrogenation products of this class of reactions are either a saturated aldehyde or an unsaturated alcohol. To avoid the formation of undesired products (mostly saturated aldehydes and ketones) and thereby an often difficult and costintensive separation process, a high selectivity in $\mathrm{C}=\mathrm{C}$ or $\mathrm{C}=\mathrm{O}$ bond hydrogenation is desirable.

It is widely accepted that the adsorption geometry of the reactant on the catalyst surface is an important factor governing the selectivity of the hydrogenation reaction. ${ }^{2-7}$ On the one hand, the adsorption geometry of an $\alpha, \beta$-unsaturated aldehyde

\footnotetext{
${ }^{a}$ Fritz-Haber-Institut der Max-Planck-Gesellschaft, Faradayweg 4-6, 14195 Berlin, Germany.E-mail: schauermann@fhi-berlin.mpg.de

${ }^{b}$ Institut für Physikalische Chemie, Christian-Albrechts-Universität zu Kiel, Max-Eyth-Str. 2, 24118 Kiel, Germany
}

or ketone can be manipulated in favor of $\mathrm{C}=\mathrm{O}$ bond hydrogenation by adding bulk substituents to the $\mathrm{C}=\mathrm{C}$ functional group. ${ }^{1,2,8}$ Acrolein, however, is the most difficult $\alpha, \beta$-unsaturated carbonyl compound to selectively hydrogenate the $\mathrm{C}=\mathrm{O}$ bond because the $\mathrm{C}=\mathrm{C}$ group is not sterically hindered by any substituent. On the other hand, the structure of the catalyst also influences the adsorption geometry of the reactant and thus may have a decisive influence on the selectivity of the conversion. Despite this fact, the effect of the catalyst structure on the selectivity in partial hydrogenation is much less understood than the effects of the molecular structure.

Our recent work on acrolein hydrogenation over a $\operatorname{Pd}(111)$ surface under well-defined ultrahigh vacuum (UHV) conditions provided new insight into the relationship between the catalyst structure and its selectivity in partial hydrogenation of acrolein. For the first time we showed that a near $100 \%$ selectivity towards hydrogenation of $\mathrm{C}=\mathrm{O}$ in acrolein is possible over $\operatorname{Pd}(111)$, while no unsaturated alcohol was formed over Pd nanoparticles. ${ }^{9}$ This was a particularly unexpected result, since numerous studies on powdered Pd catalysts have previously shown near $100 \%$ selectivity towards $\mathrm{C}=\mathrm{C}$ bond hydrogenation 
in $\alpha, \beta$-unsaturated carbonyl compounds. ${ }^{10,11}$ We explain the unexpected selectivity of $\operatorname{Pd}(111)$ by formation of a dense layer of a spectator species - oxopropyl groups - that is formed during the initial stages of the reaction and turns the surface highly selective toward $\mathrm{C}=\mathrm{O}$ bond hydrogenation.

Infrared spectroscopy is a powerful method for investigating the adsorption geometry of reactants, and their products, on well-defined catalyst surfaces. Vibrational modes of acrolein, propanal, allyl alcohol, and molecules with similar functional groups were assigned in a number of previous studies. A general overview of typical vibration frequencies can be found in a textbook by Colthup, Daly, and Wiberley. ${ }^{12}$ Hamada et al. assigned IR absorption features of gas-phase acrolein to calculated vibration frequencies in the range from $4000 \mathrm{~cm}^{-1}$ to $400 \mathrm{~cm}^{-1} .^{13}$ Puzzarini et al. studied the gas-phase structures of acrolein and their IR vibration frequencies theoretically and compared them to experimental results. Several IR absorption features were found to significantly change from trans- to cis-acrolein. ${ }^{14}$ However, Puzzari assigned IR absorption features of vinyl- and aldehyde-C-H bend modes in a way opposite to Hamdada, ${ }^{13}$ Fujii, $^{15}$ and Akita. ${ }^{16}$ Fujii et al. ${ }^{15}$ and Akita et al. ${ }^{16}$ investigated the structures of acrolein after adsorption on silver and gold films under UHV conditions. In both studies, IR vibrational modes were assigned in the range from $1800 \mathrm{~cm}^{-1}$ to about $800 \mathrm{~cm}^{-1}$. Particularly, a strong intensity of the $\mathrm{CH}_{2}$ wag vibration peak for adsorbates with molecular planes parallel to the metal surface was observed. Osaka et al. investigated the adsorption of 1,3-butadiene on $\mathrm{Au}(111)$ and $\mathrm{Ag}(111)$ surfaces. ${ }^{17}$ Loffreda et al. studied the adsorption of acrolein on $\mathrm{Pt}(111)$ by total energy and frequency calculations combined with high resolution electron energy loss spectroscopy (HREELS) experiments. ${ }^{18} \mathrm{C}-\mathrm{H}$ stretching modes of surface species during hydrogenation of acrolein and other $\alpha, \beta$-unsaturated aldehydes were studied by sum-frequency generation spectroscopy by Kliewer et al. ${ }^{19}$

Thorough experimental and theoretical studies on the vibrational modes of propanal were published by Guirgis et al. ${ }^{20}$ and Frankiss et $a l^{21}$ Guirgis studied the conformational stability and assigned vibrational modes in liquid xenon at wavenumbers up to $3500 \mathrm{~cm}^{-1}$ and Frankiss investigated the vibrational modes of normal and deuterium-labeled propanal in the gas phase. In an earlier study, vibrations of liquid and crystalline propanal were assigned experimentally by Sbrana. ${ }^{22}$ In a more general investigation, Byrne et al. studied carbonyl vibration frequencies and $\mathrm{C}-\mathrm{H}$ vibrations of saturated aliphatic aldehydes. ${ }^{23}$ Guirgis, Frankiss, Sbrana, and Byrne pointed out two typical features in the $\mathrm{C}-\mathrm{H}$ stretching region, which result from Fermi resonance between the $\mathrm{CH}$ bend overtone and the $\mathrm{CH}$ stretching fundamental at $2700-2770 \mathrm{~cm}^{-1}$ and $2800-2870 \mathrm{~cm}^{-1}$. This characteristic IR absorption of the aldehyde-CH group was studied in more detail by Pinchas ${ }^{24}$ and Eggers et al. ${ }^{25}$

A very detailed assignment of the vibrational modes of normal and isotopically labeled allyl alcohol in the gaseous, liquid, and glassy states as well as in argon and nitrogen matrices in the range from $4000 \mathrm{~cm}^{-1}$ to $200 \mathrm{~cm}^{-1}$ was performed by Silvie and Perchard. In this study, cis and gauche conformers have been identified by their IR vibration frequencies. ${ }^{26}$ In a more recent study,
Durig et al. assigned vibrational frequencies from theoretical calculations as well as from IR and Raman experiments for the four allyl alcohol conformers gauche-trans, gauche-gauche, cis-trans, and cis-gauche. ${ }^{27}$

Despite these previous combined experimental and theoretical efforts, there is still a lack of understanding of how acrolein and its derivatives change their structure upon interaction with transition metal surfaces and how their adsorption geometry depends on the adsorbate coverage. In this report, we present a comprehensive study on adsorption of acrolein, propanal, and allyl alcohol on a $\operatorname{Pd}(111)$ single crystal. Infrared reflection-absorption spectroscopy (IRAS) has been employed to investigate the molecular structures and adsorption geometries of the adsorbates as a function of adsorbate coverage. The particular focus of this study lied on determining the degree of molecular bonds perturbation upon interaction of the gas phase molecules with Pd that might have a decisive influence on the further chemical transformations of the surface species. The desorption and decomposition of the adsorbates on $\operatorname{Pd}(111)$ has been monitored by temperature programmed desorption (TPD) experiments.

\section{Experimental details}

All experiments have been performed at the Fritz-Haber-Institut, Berlin, in a UHV apparatus that was described in detail before. ${ }^{28}$ In brief, acrolein, propanal, and allyl alcohol have been dosed onto the sample through a doubly differentially pumped multichannel array source controlled by valves and shutters. The source has been operated at room temperature, and the beam diameter has been chosen to exceed the sample size. The $\operatorname{Pd}(111)$ single crystal has been cleaned prior to use by repeated cycles of $\mathrm{Ar}^{+}$ion bombardment at room temperature, annealing at $1000 \mathrm{~K}$ and oxidation in $1 \times 10^{-6} \mathrm{mbar}_{2}$ at $750 \mathrm{~K}$ to remove residual carbon. The final cleaning cycle has been stopped after annealing. The flatness and cleanliness of the $\operatorname{Pd}(111)$ single crystal surface has been checked by low energy electron diffraction (LEED) and IRAS measurements of adsorbed CO.

IRAS data have been acquired using a vacuum FourierTransform infrared (FT-IR) spectrometer (Bruker IFS 66v/S) with a spectral resolution of $2 \mathrm{~cm}^{-1}$ and a mid-infrared (MIR) polarizer and p-polarized IR light. TPD experiments have been carried out in the same vacuum system and by using an automated quadrupole mass spectrometer (QMS) system (Hiden Analytics) to monitor the partial pressures of the desorbing molecules: acrolein (parent ion at 56 a.m.u.), $\mathrm{H}_{2}$ : (2 a.m.u.), propanal (parent ion and main fragment at 58 a.m.u.), propenol (parent ion at 58 a.m.u., main fragment at 57 a.m.u. and further prominent fragment at 31 a.m.u.), propanol (parent ion at 60 a.m.u., main fragment at 31 a.m.u.). Prior to each TPD cycle, a blank experiment was carried out to monitor feasible evolution of hydrogen from the heating element and other sources. Some minor hydrogen evolution was obtained at the very beginning of the heating cycle (close to $100 \mathrm{~K}$ ), which results in minor hydrogen signals ( $2 \mathrm{amu}$ ) that can be seen in all TPD data. These small peaks have to be considered as an experimental artefact. No hydrogen 
evolution at temperatures higher that $200 \mathrm{~K}$ was obtained in the blank experiments.

Shortly before each experiment the sample has been flash annealed to $600 \mathrm{~K}$ before cooling to $120 \mathrm{~K}$. Acrolein (Fluka, 95\% purity), propanal (Acros Organics, $>99 \%$ purity), and allyl alcohol (Aldrich, $>99 \%$ purity) have been purified prior to their exposure by repeated freeze-pump-thaw cycles.

\section{Results}

In this study, the adsorption of acrolein, propanal, and allyl alcohol was investigated on $\mathrm{Pd}(111)$ at $120 \mathrm{~K}$ under well-defined UHV conditions by IRAS. The molecular structures and the adsorption geometry of the adsorbates were studied as a detailed function of coverage. To obtain a reference for an unperturbed molecule, the IR spectra were recorded at multilayer coverages, at which the majority of the adsorbed molecules do not directly interact with the surface. These reference spectra were compared with those obtained at sub-monolayer coverages to investigate the perturbation of chemical bonds by the interaction with Pd.

It is important to note that the adsorption geometry of adsorbates on metal surfaces can be deduced from their IR spectra based on the metal surface selection rule (MSSR). ${ }^{29-31}$ According to the MSSR, only the component of the dynamic dipole moment perpendicular to the metal surface can be detected, while vibrations parallel to the surface are strongly attenuated by formation of an image dipole in the substrate. Hence, characteristic intensity distributions of IR absorption peaks in sub-monolayer coverage regime can give information on the adsorption geometry of the corresponding adsorbate.

Three main spectral regions can be distinguished for all investigated molecules, which are characteristic for $\mathrm{C}-\mathrm{H}$ stretching vibrations (3100-2700 $\left.\mathrm{cm}^{-1}\right), \mathrm{C}=\mathrm{O}$ and $\mathrm{C}=\mathrm{C}$ stretching vibrations (1800-1600 $\left.\mathrm{cm}^{-1}\right)$ as well as $\mathrm{C}-\mathrm{H}$ deformation and
C-C stretching vibrations $\left(<1500 \mathrm{~cm}^{-1}\right)$. The exact assignment of the IR vibration peaks for each compound will be discussed in the following sections.

\subsection{Adsorption of acrolein}

Fig. 1(a) shows the coverage-dependent evolution of IR spectra of acrolein on $\operatorname{Pd}(111)$ from the sub-monolayer to the multilayer regime. The numbers next to the spectra indicate the particular acrolein coverages expressed as an absolute number of adsorbed acrolein molecules per $\mathrm{cm}^{2}$, which was determined based on sticking coefficient measurements and the absolute molecular beam flux. Table 1 summarizes the assignment of vibrational modes to the observed IR absorption features of the different acrolein species on the $\operatorname{Pd}(111)$. In this table, we tentatively distinguish four different species, which we refer to as types $\mathrm{A}, \mathrm{B}, \mathrm{C}$, and D. Coverages up to $2.7 \times 10^{14}$ molecules per $\mathrm{cm}^{2}$ (corresponding to less than 0.2 acrolein molecules per surface Pd atom; species A and B in Table 1), at which the most strongly perturbed species appear, can be assigned to the sub-monolayer regime. The surface coverage of $3.6 \times 10^{14}$ molecules per $\mathrm{cm}^{2}$ (corresponding to 0.25 acrolein per surface Pd atom; species C in Table 1) is related to the full monolayer coverage. Finally, the multilayer adsorption regime (species D in Table 1) starts from the exposure of $5.4 \times 10^{14}$ molecules per $\mathrm{cm}^{2}$. With increasing exposure, constantly growing intensities of all vibrational features were observed for species $D$ that confirm the formation of acrolein ice. The IR spectra of species $D$ can serve as a reference for an unperturbed molecule.

3.1.1. Unperturbed acrolein in multilayer. First, we will address the multilayer regime of acrolein adsorption and identify the associated vibrational bands characteristic to a nearly unperturbed acrolein molecule. Here, a large number of IR absorption modes can be distinguished. In the $\mathrm{C}-\mathrm{H}$ stretching region, IR vibrations are observed at $2857 \mathrm{~cm}^{-1}, 2820 \mathrm{~cm}^{-1}$, $2766 \mathrm{~cm}^{-1}$, and $2705 \mathrm{~cm}^{-1}$. Based on the previous studies,
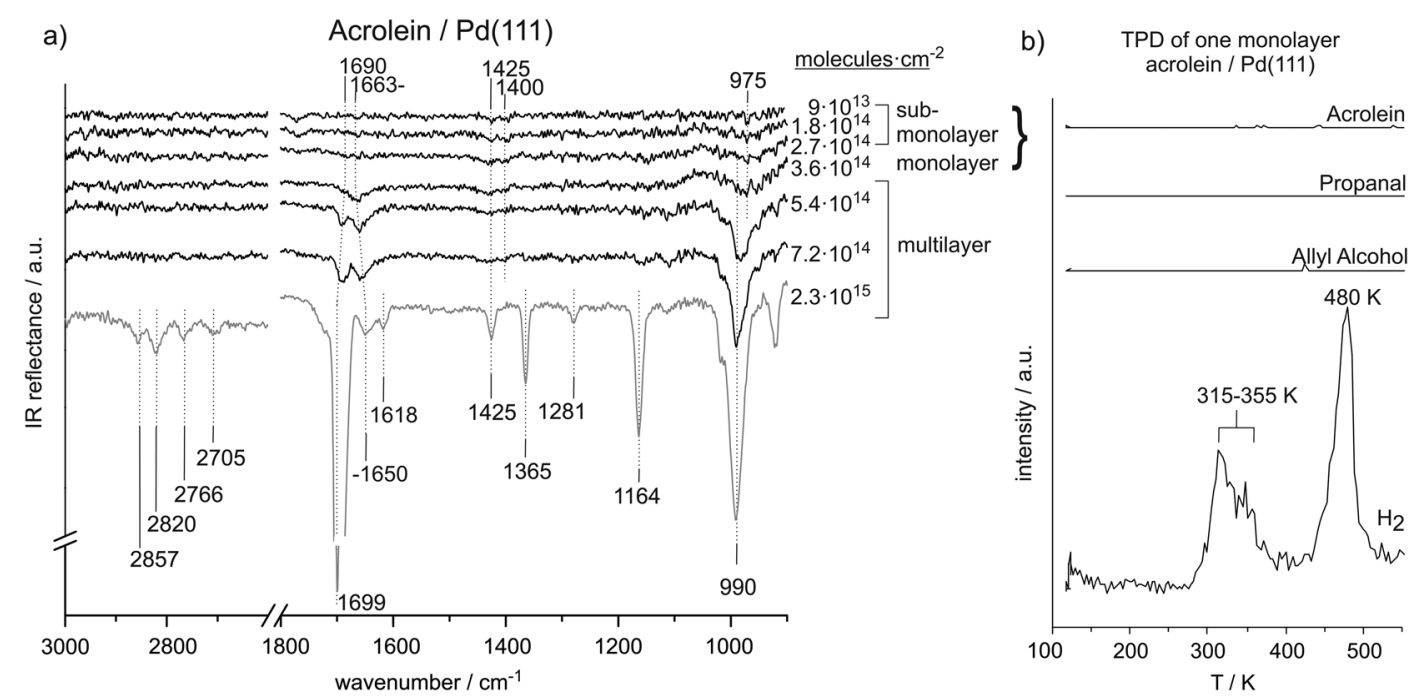

Fig. 1 (a) IR spectra of acrolein on Pd(111) from sub-monolayer to multilayer coverage recorded at $120 \mathrm{~K}$. (b) TPD study after adsorption of a monolayer of acrolein $\left(3.6 \times 10^{14} \mathrm{~cm}^{-2}\right)$ on $\mathrm{Pd}(111)$. 
Table 1 Assignment of IR vibrational modes of acrolein on Pd(111) at $120 \mathrm{~K}$

\begin{tabular}{|c|c|c|c|c|c|}
\hline Mode & \multicolumn{4}{|l|}{ IR frequency $/ \mathrm{cm}^{-1}$} & Ref./cm ${ }^{-1}$ \\
\hline$\nu(\mathrm{CH})_{\mathrm{v}}$ & & & & & $3069,{ }^{13} 3092-3077^{12}$ \\
\hline$\nu_{\mathrm{s}}\left(\mathrm{CH}_{2}\right)$ & & & & 2820 & $2998,{ }^{13} 3025-3012^{12}$ \\
\hline \multirow[t]{2}{*}{$2 \delta(\mathrm{CH})_{\mathrm{C}=\mathrm{O}}$} & & & & $2766^{a}$ & $2772,^{24} 2800^{13}$ \\
\hline & & & & & $\begin{array}{l}2830-2810^{12} \\
2867-2818^{20}\end{array}$ \\
\hline & & & & & $2720-2695^{12}$ \\
\hline \multirow{2}{*}{$\nu(\mathrm{C}=\mathrm{O})$} & & & $1663-1650$ & $1700-1690$ & $1672-1670(\text { on } \mathrm{Ag})^{16}$ \\
\hline & & & & & $\begin{array}{l}1684-1670{\text { (on } \mathrm{Ag})^{15}}^{1724(\mathrm{gas})^{13}} \\
17\end{array}$ \\
\hline \multirow[t]{2}{*}{$\nu(\mathrm{C}=\mathrm{C})$} & & & & 1618 & $1618-1603,,^{15} 1625^{13}$ \\
\hline & & & & & $1644-1617^{12}$ \\
\hline & & & & & $1275,^{13} 1360^{14}$ \\
\hline$\nu(\mathrm{C}-\mathrm{C})$ & & & & 1164 & $1169-1159,{ }^{15} 1158^{13,14}$ \\
\hline \multirow{5}{*}{$\omega_{\mathrm{T}}\left(\mathrm{HC}=\mathrm{CH}_{2}\right)$} & & & & & $1165-1159^{16}$ \\
\hline & (975) & $(975)$ & $(990)$ & (990) & $1018-841^{15}$ \\
\hline & & & & & $1020-950^{16}$ \\
\hline & & & & & $1022-1002^{17 b}$ \\
\hline & & & & & $993,^{13} 995-985^{12}$ \\
\hline
\end{tabular}

$\nu=$ stretching, $\nu_{\mathrm{a}}=$ asymmetric stretching, $\nu_{\mathrm{s}}=$ symmetric stretching $\delta=$ bending, $\omega_{\mathrm{T}}=$ trans -wag vibration, $\mathrm{C}=\mathrm{O}=$ aldehyde group, $\mathrm{C}=\mathrm{C}=$ vinyl group. ${ }^{a}$ Fermi resonance. ${ }^{b}$ Vibration in 1,3 -butandiene.

we assign the two higher wavenumber peaks to $\mathrm{CH}_{2}$ asymmetric $\left(2857 \mathrm{~cm}^{-1}\right)$ and symmetric stretching $\left(2820 \mathrm{~cm}^{-1}\right)$ modes. Previously, the two $\mathrm{CH}_{2}$ stretching modes were observed near $3000 \mathrm{~cm}^{-1}$ and $3100 \mathrm{~cm}^{-1}$ and thus at higher frequencies. ${ }^{12,13}$ The two features at $2766 \mathrm{~cm}^{-1}$ and $2705 \mathrm{~cm}^{-1}$ can be assigned to the first overtone of the aldehyde- $\mathrm{C}-\mathrm{H}$ bend and the aldehyde-C- $\mathrm{H}$ stretching fundamental vibrations. The appearance of the two peaks is known to typically appear in aldehydes and was previously explained by strong Fermi resonance. ${ }^{12,20,24}$

In the $\mathrm{C}=\mathrm{C}$ and $\mathrm{C}=\mathrm{O}$ stretching region, a very pronounced IR vibration is observed at $1690-1700 \mathrm{~cm}^{-1}$ and weaker bands are observed at $1650 \mathrm{~cm}^{-1}$ and $1618 \mathrm{~cm}^{-1}$. The bands at $1690-1700 \mathrm{~cm}^{-1}$ and at $1650 \mathrm{~cm}^{-1}$ are assigned to the $\mathrm{C}=\mathrm{O}$ stretching modes at multilayer and monolayer acrolein coverages, respectively. The frequency of the $\mathrm{C}=\mathrm{O}$ vibration at multilayer acrolein coverages increases with coverage from $1690 \mathrm{~cm}^{-1}$ at $5.4 \times 10^{14}$ molecules per $\mathrm{cm}^{2}$ to $1699 \mathrm{~cm}^{-1}$ at $2.3 \times 10^{15}$ molecules per $\mathrm{cm}^{2}$ and thus shifts closer to the previously reported value of $1724 \mathrm{~cm}^{-1}$ for acrolein in the gas phase. ${ }^{13}$ The $\mathrm{C}=\mathrm{O}$ vibrational band associated with a monolayer coverage of acrolein at $1650 \mathrm{~cm}^{-1}$ is red-shifted relative to that in multilayer acrolein due to the interaction of the $\mathrm{C}=\mathrm{O}$ vibration with the surface. The $\mathrm{C}=\mathrm{C}$ stretching vibration at $1618 \mathrm{~cm}^{-1}$ appears in the frequency range reported in literature. ${ }^{13,15}$ Note that the intensity of the $\mathrm{C}=\mathrm{C}$ vibrational band is considerably lower than that one of the $\mathrm{C}=\mathrm{O}$ bond due to significantly lower dynamic dipole moment. It should be noted that previously published experimental assignment of acrolein gasphase modes suggest no significant coupling between $\mathrm{C}=\mathrm{O}$ and
$\mathrm{C}=\mathrm{C}$ vibrations. ${ }^{32}$ It should be kept in mind, however, that this can change, especially when acrolein is adsorbed on metals, and the modes should be considered rather as coupled modes having mostly $\mathrm{C}=\mathrm{C}$ or $\mathrm{C}=\mathrm{O}$ character.

In the region below $1500 \mathrm{~cm}^{-1}$, well-separated IR absorption features appear at $1425 \mathrm{~cm}^{-1}, 1365 \mathrm{~cm}^{-1}, 1281 \mathrm{~cm}^{-1}$, $1164 \mathrm{~cm}^{-1}$, and $990 \mathrm{~cm}^{-1}$. The precise assignment of the bands in this vibrational region is quite difficult due in part to contradictory assignments of these bands in the literature. Based on the previous reports, the vibration at $1425 \mathrm{~cm}^{-1}$ can be assigned to the $\mathrm{CH}_{2}$ scissor bending mode and the IR absorption at $990 \mathrm{~cm}^{-1}$ to a deformation of the $\mathrm{HC}=\mathrm{CH}_{2}$ unit, possibly a trans-wag mode, which is a $=\mathrm{CH}_{2}$ twist coupled with a $\mathrm{H}-\mathrm{C}=$ out-of-plane bend vibration. The vibration at $1164 \mathrm{~cm}^{-1}$ is related to the $\mathrm{C}-\mathrm{C}$ stretching vibration. The vibrational modes at $1365 \mathrm{~cm}^{-1}$ and $1281 \mathrm{~cm}^{-1}$ can be assigned to bending of the aldehyde- and vinyl-C-H bonds. Previously, most studies assigned the higher wavenumber peak to the aldehyde-C-H group and the lower frequency peak to the vinyl-C-H group; ${ }^{12,13,16,18}$ however, we also found the reversed assignment. ${ }^{14}$ In literature, the $\mathrm{C}-\mathrm{C}$ stretching was observed at 1169-1158 $\mathrm{cm}^{-113-16}$ and the $\mathrm{CH}_{2}$ scissor deformation in acrolein was reported near $1425 \mathrm{~cm}^{-1} \cdot{ }^{13,14,16}$ The strong IR absorption near $975-990 \mathrm{~cm}^{-1}$ was related to the $\mathrm{HC}=\mathrm{CH}_{2}$ unit; however, previous publications assigned these features to different modes, such as $\mathrm{CH}$ bend, ${ }^{15,16}$ $\mathrm{CH}_{2}$ wag $^{16}$ or $\mathrm{CH}_{2}$ twist $^{17}$ vibrations. Colthup et al. referred to this intense IR absorption as $\mathrm{HC}=\mathrm{CH}_{2}$ trans-wag mode. ${ }^{12}$

3.1.2. Acrolein at monolayer coverage. Significant changes in the infrared spectrum of acrolein adsorbed on $\operatorname{Pd}(111)$ 
occurs when the coverage is decreased from multilayers, in which the molecules are relatively unperturbed, to monolayer coverage. At monolayer coverage, the most prominent peak is observed at $1663 \mathrm{~cm}^{-1}$ and thus in the typical range for a $\mathrm{C}=\mathrm{O}$ stretching vibration. It shifts to $1650 \mathrm{~cm}^{-1}$ with increasing coverage. The position of this band is about $30-40 \mathrm{~cm}^{-1}$ lower than the $\mathrm{C}=\mathrm{O}$ stretching vibration in acrolein multilayer and about $60 \mathrm{~cm}^{-1}$ lower than the $\mathrm{C}=\mathrm{O}$ stretching frequency determined in previous studies on acrolein in the gas phase $\left(1724 \mathrm{~cm}^{-1}\right) .{ }^{33}$ Further noticeable vibrations are the $\mathrm{CH}_{2}$ scissor vibration at $1425 \mathrm{~cm}^{-1}$ and the $\mathrm{HC}=\mathrm{CH}_{2}$ trans-wag mode near $990 \mathrm{~cm}^{-1}$. These frequencies are similar to those for acrolein adsorbed in multilayers. Nearly zero intensity is observed for the bands at $1365 \mathrm{~cm}^{-1}$ and $1164 \mathrm{~cm}^{-1}$ and the $\mathrm{C}-\mathrm{H}$ stretching vibrations in the range from $2705 \mathrm{~cm}^{-1}$ to $2857 \mathrm{~cm}^{-1}$.

3.1.3. Acrolein in sub-monolayer coverage. In the submonolayer regime further pronounced changes occur as compared to unperturbed acrolein. Most prominently, no vibrational features in the range of $\mathrm{C}=\mathrm{O}$ and $\mathrm{C}=\mathrm{C}$ vibrations are observed. Low intensity IR vibrations are detected at $1425 \mathrm{~cm}^{-1}, 1400 \mathrm{~cm}^{-1}$, and $975 \mathrm{~cm}^{-1}$. All of these IR absorption peaks can assigned to typical deformation modes of the $\mathrm{CH}_{2}$ group. Based on the previous reports, we assign the vibrations at $1425 \mathrm{~cm}^{-1}$ and $1400 \mathrm{~cm}^{-1}$ to $\mathrm{CH}_{2}$ scissor bend vibrations and the intense IR absorption at $975 \mathrm{~cm}^{-1}$ to a deformation of the trans-wag mode of the $\mathrm{HC}=\mathrm{CH}_{2}$ unit.

The vibration at $1400 \mathrm{~cm}^{-1}$ appears at relatively low wavenumber compared to typical $\mathrm{CH}_{2}$ scissor frequencies reported in literature and thus points to a possible perturbation of the $\mathrm{CH}_{2}$ group. We refer to this species as type A in Table 1. This perturbation becomes less pronounced, and the band shifts to a frequency characteristic of an unperturbed molecule $\left(1425 \mathrm{~cm}^{-1}\right)$ with increasing coverage. We refer to this surface species with less perturbed $\mathrm{CH}_{2}$ group as to species B. However, it should be kept in mind that the transition from A to B arises most likely from the increasing coverage and a concomitant increase of a dipole-dipole coupling that might results in the frequency shifts. The distinguishing between the species A and B should not be misunderstood as referring to two chemically and/or structurally different adsorbates but rather to the same surface species merely exhibiting different vibrational frequency due to dipole coupling effects. The IR absorption at $975 \mathrm{~cm}^{-1}$ appears in all IR spectra recorded in sub-monolayer regime. Note that the first two spectra also contain a band at $1780 \mathrm{~cm}^{-1}$, whose intensity is comparable to the bands related to the $\mathrm{C}-\mathrm{H}$ deformation vibrations (1400-1425 $\mathrm{cm}^{-1}$ ). As this band completely disappears with growing acrolein coverage and is not present in acrolein multilayer spectra, this vibration is most likely related to some surface contamination (e.g., CO molecules adsorbed from the background), which is replaced by acrolein with growing exposure.

3.1.4. TPD of acrolein. Fig. 1(b) shows a TPD experiment carried out on $\operatorname{Pd}(111)$ with pre-adsorbed of $1 \mathrm{ML}$ acrolein $\left(3.6 \times 10^{14} \mathrm{~cm}^{-2}\right.$ molecules $\left.\mathrm{cm}^{-2}\right)$. No desorption of acrolein, allyl alcohol or propanal were detected; however, pronounced hydrogen peaks appear at between 315 and $355 \mathrm{~K}$ and at $480 \mathrm{~K}$, indicating acrolein decomposition. This observation points to a complete decomposition of acrolein monolayer upon heating. Note that surface adsorbed hydrogen desorbs from clean $\mathrm{Pd}(111)$ surface at $300 \mathrm{~K}$, so that peak at 315-355 K observed in our experiment cannot be desorption limited and must arise from acrolein decomposition. This desorption pattern consisting of two peaks is typical for decomposition of a variety of hydrocarbons on $\mathrm{Pd}^{34}{ }^{3}$ Previously we investigated the temperatureprogrammed desorption and decomposition of isophorone on $\operatorname{Pd}(111)$ and observed a similar sequential decomposition resulting in $\mathrm{H}_{2}$ desorption peaks at $325-345 \mathrm{~K}$ and $485 \mathrm{~K}^{35}$ Decomposition of acrolein to hydrogen does not result in self-hydrogenation of intact acrolein molecules as it was previously reported for some other hydrocarbons, ${ }^{36}$ as indicated by absence of allyl alcohol or propanal in the desorption traces.

\subsection{Adsorption of propanal}

Fig. 2(a) shows the coverage dependent evolution of IR spectra of propanal on $\mathrm{Pd}(111)$ from the sub-monolayer to the multilayer coverage at $120 \mathrm{~K}$. The absolute propanal coverages are located to the right of the corresponding spectra. Coveragedependent changes of IR absorption features suggest three coverage regimes: sub-monolayer, monolayer, and multilayer. The formation of a complete monolayer requires the propanal exposures in the range of $3.6 \times 10^{14}$ to $5.4 \times 10^{14}$ molecules per $\mathrm{cm}^{2}$; above this coverage the propanal multilayer is formed. A clear sub-monolayer regime is observed below $2.7 \times 10^{14}$ propanal molecules per $\mathrm{cm}^{2}$. Table 2 gives an overview of all IR vibrational peaks at sub-monolayer, monolayer and multilayer propanal coverages observed in this study and an overview of the assignments from literature. ${ }^{12,20-24,37-40}$

3.2.1. Unperturbed propanal molecule in multilayer. At multilayer propanal coverage, several modes are observed at frequencies typical for $\mathrm{C}-\mathrm{H}$ stretching vibrations. IR absorption peaks appear at $2987 \mathrm{~cm}^{-1}, 2970 \mathrm{~cm}^{-1}, 2904 \mathrm{~cm}^{-1}, 2884 \mathrm{~cm}^{-1}$, $2868 \mathrm{~cm}^{-1}$, and $2752 \mathrm{~cm}^{-1}$. IR absorption near $2987 \mathrm{~cm}^{-1}$, $2943 \mathrm{~cm}^{-1}, 2904 \mathrm{~cm}^{-1}$, and $2987 \mathrm{~cm}^{-1}$ appear at typical frequencies for $\mathrm{CH}_{3}$ and $\mathrm{CH}_{2}$ stretching vibration modes. Based on assignments of IR vibrations of propanal reported in literature $^{20-22}$ and on our previous combination of density functional theory (DFT) and IRAS studies on adsorbed isophorone, ${ }^{41}$ the vibrations at $2987 \mathrm{~cm}^{-1}$ and $2884 \mathrm{~cm}^{-1}$ are assigned to $\mathrm{CH}_{3}$ asymmetric and symmetric stretching, correspondingly, and the IR absorption at $2943 \mathrm{~cm}^{-1}$ and $2904 \mathrm{~cm}^{-1}$ are related to the $\mathrm{CH}_{2}$ asymmetric and symmetric stretching modes. The features at $2868 \mathrm{~cm}^{-1}$ and $2752 \mathrm{~cm}^{-1}$ are both assigned to the aldehyde$\mathrm{C}-\mathrm{H}$ group. As earlier discussed for acrolein, these two peaks are known to result from strong Fermi resonance between the first overtone of the $\mathrm{CH}$ bending and $\mathrm{CH}$ stretching fundamental. ${ }^{20,21,23,24}$ The $\mathrm{CH}_{3}$ asymmetric $\left(2987 \mathrm{~cm}^{-1}\right.$ ) and symmetric stretching $\left(2884 \mathrm{~cm}^{-1}\right)$ vibrations are in the range of those previously reported at $2992-2980 \mathrm{~cm}^{-120-22}$ and 2905$2880 \mathrm{~cm}^{-1},{ }^{20,21}$ respectively. The $\mathrm{CH}_{2}$ asymmetric stretching was found at 2914-2899 $\mathrm{cm}^{-1} \cdot{ }^{20,22}$ However, none of the literature data refers to propanal on a metal surface. 
a) $\quad$ Propanal / Pd(111)

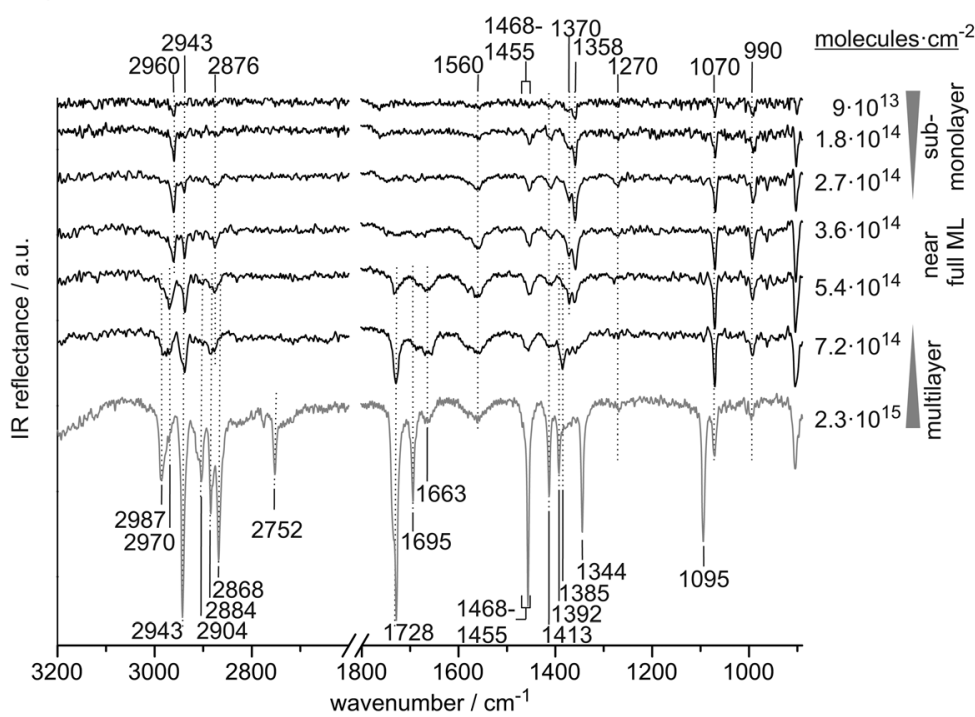

b) TPD after adsorption of $2.3 \cdot 10^{15}$ propanal $/ \mathrm{cm}^{2}$

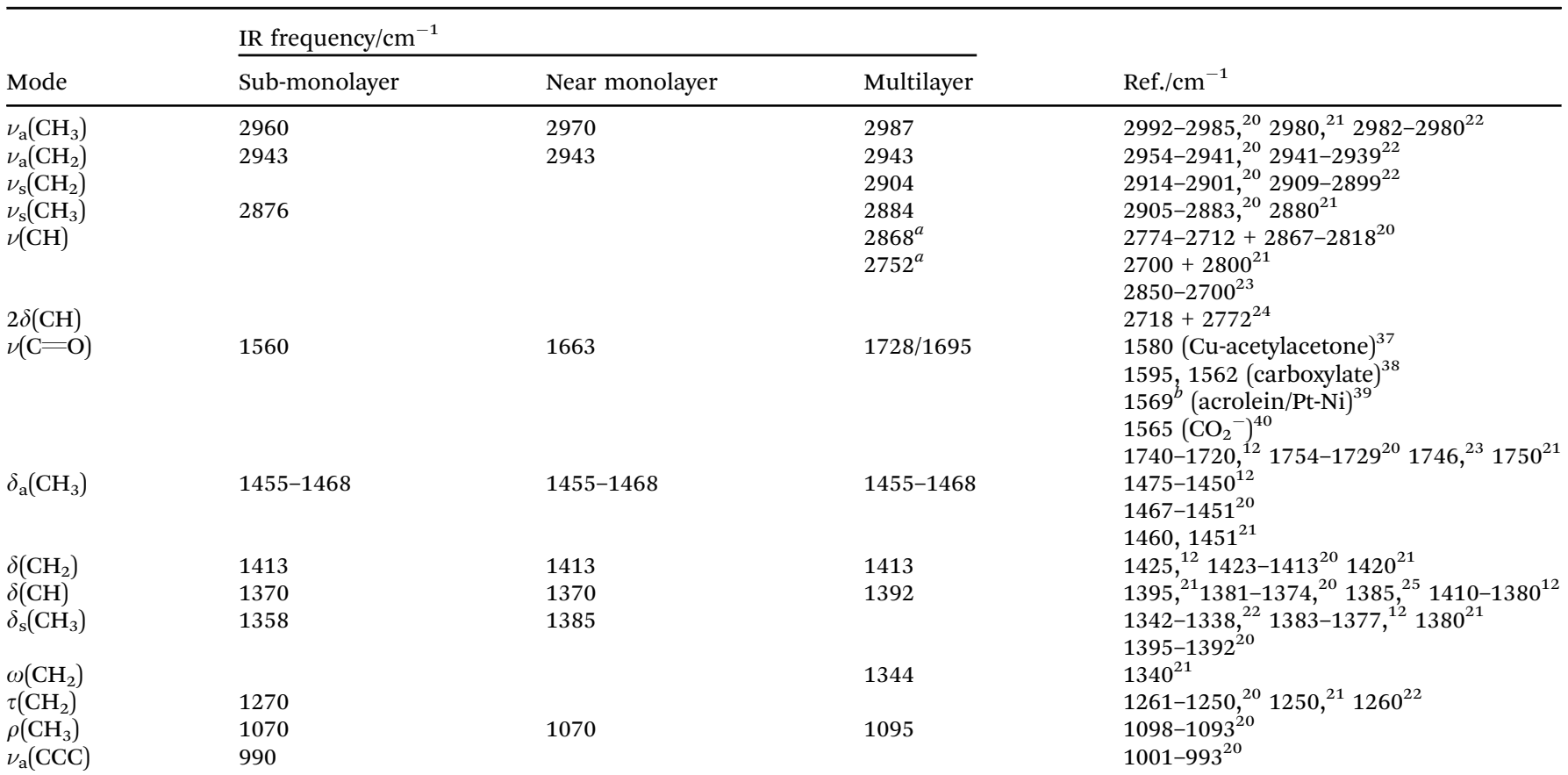

Fig. 2 (a) IR spectra of propanal on Pd(111) from the sub-monolayer to multilayer regime recorded at $120 \mathrm{~K}$. (b) TPD after deposition of about six layers of propanal on $\mathrm{Pd}(111)$.

Table 2 Assignment of IR vibrations of propanal on $\operatorname{Pd}(111)$ at $120 \mathrm{~K}$

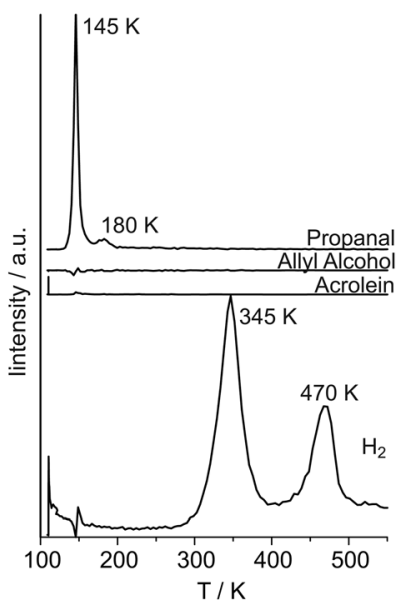


from literature. Previously, $\mathrm{CH}_{3}$ asymmetric and symmetric bending were found in the ranges from $1475-1413 \mathrm{~cm}^{-112,20,21}$ and $1395-1338 \mathrm{~cm}^{-1} \cdot{ }^{20-22} \mathrm{CH}_{2}$ bending was reported at $1425-$ $1413 \mathrm{~cm}^{-112,20,21}$ and $\mathrm{CH}_{2}$ wagging at $1340 \mathrm{~cm}^{-1} \cdot{ }^{21} \mathrm{CH}$ bending was found at $1410-1374 \mathrm{~cm}^{-112,20,21,25}$ and $\mathrm{CH}_{3}$ rocking was found at $1098-1093 \mathrm{~cm}^{-1} .^{20}$

3.2.2. Propanal at monolayer coverage. The number of IR vibrational peaks decreases as the propanal coverage is decreased from multilayer $\left(2.3 \times 10^{15}\right.$ molecules per $\left.\mathrm{cm}^{2}\right)$ to near-multilayer coverage $\left(3.6 \times 10^{14}\right.$ molecules per $\left.\mathrm{cm}^{2}\right)$. Based on the absolute number of adsorbed molecules (0.36-0.25 propanal molecules per surface Pd atom) and strong changes of the IR spectral features, we refer to this coverage regime as to the nearmonolayer coverage. As compared to unperturbed propanal in a multilayer, the IR absorption features assigned to the $\mathrm{CH}_{3}$ and $\mathrm{CH}_{2}$ symmetric stretching modes disappear close to a monolayer coverage as well as the peaks related to the $\mathrm{CH}$ group. The absence of these vibrational modes is most likely explained by a parallel orientation of the respective dynamic dipole moments to the metal surface, which would result in the vanishing of this vibration due to the MSSR. ${ }^{42}$ The vibration at $2943 \mathrm{~cm}^{-1}$, which has been related to the $\mathrm{CH}_{2}$ asymmetric stretching in propanal multilayers, remains at the same frequency. The $\mathrm{CH}_{3}$ asymmetric stretching frequency, in contrast, decreases from $2987 \mathrm{~cm}^{-1}$ at multilayer coverage to $2970 \mathrm{~cm}^{-1}$ at monolayer coverage.

At near-monolayer coverage, the $\mathrm{C}=\mathrm{O}$ stretching frequency (1663 $\mathrm{cm}^{-1}$ ) is significantly lower than that of multilayer coverages (1728 and $1695 \mathrm{~cm}^{-1}$ ), which suggests a significant weakening of the $\mathrm{C}=\mathrm{O}$ bond and hence to a strong interaction of this group with the Pd surface.

In the region of the bending vibrations, peaks are observed at $1455-1468 \mathrm{~cm}^{-1}, 1413 \mathrm{~cm}^{-1}, 1385 \mathrm{~cm}^{-1}, 1370 \mathrm{~cm}^{-1}$, and $1070 \mathrm{~cm}^{-1}$. Similar to those observed at higher coverages, the vibrations at $1455-1468 \mathrm{~cm}^{-1}$ and $1413 \mathrm{~cm}^{-1}$ are assigned to $\mathrm{CH}_{3}$ asymmetric bending and the $\mathrm{CH}_{2}$ bending. However, the $\mathrm{CH}_{3}$ symmetric bending and $\mathrm{CH}$ bending modes can tentatively be resolved as the two separated features at $1385 \mathrm{~cm}^{-1}$ and $1370 \mathrm{~cm}^{-1}$. The vibration at $1070 \mathrm{~cm}^{-1}$ is assigned to a $\mathrm{CH}_{3}$ rocking mode which is slightly shifted to lower frequencies relative to higher coverages.

3.2.3. Propanal at sub-monolayer coverage. Compared to acrolein, a relatively large number of IR absorption features are observed at low propanal concentration on the $\operatorname{Pd}(111)$ surface. Several prominent IR vibrational peaks appear in the sub-monolayer regime and saturate near the monolayer coverage. We assume that these vibrational modes are related to adsorbates that are formed in the first monolayer and remain present on the surface at multilayer coverages.

At surface coverages ranging from $9 \times 10^{13}$ to $2.7 \times 10^{14}$ molecules per $\mathrm{cm}^{2}(0.06-0.18$ propanal molecules per surface Pd atom), pronounced IR absorption peaks appear in the region of the $\mathrm{C}-\mathrm{H}$ stretching vibrations at $2960 \mathrm{~cm}^{-1}$, $2943 \mathrm{~cm}^{-1}$, and $2876 \mathrm{~cm}^{-1}$. The mode at $2960 \mathrm{~cm}^{-1}$ is assigned to the $\mathrm{CH}_{3}$ asymmetric stretching and the vibration $2876 \mathrm{~cm}^{-1}$ is related to the $\mathrm{CH}_{3}$ symmetric stretching. Thus, the asymmetric stretching mode appears at $27 \mathrm{~cm}^{-1}$ lower frequency compared to the multilayer species while the symmetric mode only decreases by $8 \mathrm{~cm}^{-1}$. The frequency of the $\mathrm{CH}_{2}$ asymmetric stretching at $2943 \mathrm{~cm}^{-1}$ is found to be independent of the surface coverage.

In the region typical of $\mathrm{C}=\mathrm{O}$ stretching vibrations, no $\mathrm{IR}$ absorption features can be identified at sub-monolayer coverages. At $1560 \mathrm{~cm}^{-1}$, however, an IR vibration is observed, which is present neither in propanal nor in other aldehydes and can therefore not be related to any vibration of intact propanal molecules. Nevertheless, similar vibration frequencies have been observed before. Murillo et al. observed a vibration at $1569 \mathrm{~cm}^{-1}$ in HREELS experiments of acrolein adsorbed on Pt-Ni-Pt(111) and $\mathrm{Pt}-\mathrm{Co}-\mathrm{Pt}(111)$ surfaces and assigned it to a $\mathrm{C}-\mathrm{O}$ stretching vibration of acrolein adsorbed in a di- $\sigma-\mathrm{C}-\mathrm{O}$ configuration. ${ }^{39}$ Furthermore, the $\mathrm{COO}^{-}$asymmetric stretching vibration of a propanoate species on oxide surfaces were found at $1595 \mathrm{~cm}^{-138}$ and $1565 \mathrm{~cm}^{-1}, 40$ and the $\mathrm{C}=\mathrm{O}$ stretching frequencies of $\beta$-diketone complexes with $\mathrm{Cu}$ were reported to appear down to $1524 \mathrm{~cm}^{-1} \cdot{ }^{37}$ Hence, this IR absorption feature could point to a strong weakening of the carbonyl group because of the tendency of the oxygen to attract electrons $\mathrm{C}=\mathrm{O} \leftrightarrow \mathrm{C}^{+}-\mathrm{O}^{-}$. The polarized form could gain in importance, if the charge is stabilized by the Pd surface. However, a di- $\sigma$ configuration as observed by Murillo et al. for acrolein on $\mathrm{Pt}-\mathrm{Ni}-\mathrm{Pt}(111)$ and $\mathrm{Pt}-\mathrm{Co}-\mathrm{Pt}(111)$ seems unlikely here since a di- $\sigma$ bounded $\mathrm{C}-\mathrm{O}$ group would be parallel to the Pd surface and thus not detectable by IRAS due to the MSSR.

In the region below $1500 \mathrm{~cm}^{-1}$, IR vibrations are detected at 1468-1455 $\mathrm{cm}^{-1}, 1413 \mathrm{~cm}^{-1}, 1370 \mathrm{~cm}^{-1}, 1358 \mathrm{~cm}^{-1}$, $1270 \mathrm{~cm}^{-1}, 1070 \mathrm{~cm}^{-1}$, and $990 \mathrm{~cm}^{-1}$. IR absorption features at $1468-1455 \mathrm{~cm}^{-1}, 1413 \mathrm{~cm}^{-1}$, and $1070 \mathrm{~cm}^{-1}$ appear mainly independent of coverage and are assigned to $\mathrm{CH}_{3}$ asymmetric bend, $\mathrm{CH}_{2}$ bend, and $\mathrm{CH}_{3}$ vibrations. The vibrations at $1370 \mathrm{~cm}^{-1}$ and $1358 \mathrm{~cm}^{-1}$ strongly indicate $\mathrm{CH}$ bending or $\mathrm{CH}_{3}$ umbrella bending modes; a clear assignment, however, is difficult. Nevertheless, the mode at $1358 \mathrm{~cm}^{-1}$ is characteristic of the low-coverage species. With higher certainty, we assigned the peaks at $1270 \mathrm{~cm}^{-1}$ and $990 \mathrm{~cm}^{-1}$ to $\mathrm{CH}_{2}$ twist and $\mathrm{CCC}$ asymmetric stretching modes. The latter two vibrational features do not appear in the spectra at higher coverages. Previously, $\mathrm{CH}_{2}$ twist vibrations were observed at $1261-1250 \mathrm{~cm}^{-1}, \mathrm{CH}_{3}$ rocking was found at 1098-1093 $\mathrm{cm}^{-1}$, and CCC asymmetric stretching modes were reported at $1001-993 \mathrm{~cm}^{-1}$. $^{20}$

3.2.4. TPD of propanal. Fig. $2 b$ shows a TPD experiment starting from approximately six layers of propanal on $\operatorname{Pd}(111)$. Desorption of acrolein, allyl alcohol, propanal and hydrogen were followed. Neither acrolein nor allyl alcohol are observed in the gas phase. Propanal, however, appears in a strong and sharp desorption peak at $145 \mathrm{~K}$ and in a weak feature at $180 \mathrm{~K}$. Hydrogen desorption is observed near $345 \mathrm{~K}$ and $470 \mathrm{~K}$. The two hydrogen peaks point to sequential decomposition resulting in a reaction-limited formation of $\mathrm{H}_{2}$. The two propanal desorption peaks correspond to desorption of weakly bound (presumably physisorbed) molecules from multilayer at $145 \mathrm{~K}$ and stronger bound (chemisorbed) species desorbing form monolayer at $180 \mathrm{~K}$. 


\subsection{Adsorption of allyl alcohol}

Fig. 3a shows a coverage-dependent IRAS study of allyl alcohol adsorbed on $\operatorname{Pd}(111)$ at $120 \mathrm{~K}$. We distinguish between a low coverage regime up to $3.6 \times 10^{14}$ ally alcohol molecules per $\mathrm{cm}^{2}$ (corresponding to 0.24 allyl alcohol molecules per surface $\mathrm{Pd}$ atom) and a high coverage regime starting at $5.4 \times$ $10^{14}$ molecules per $\mathrm{cm}^{2}$ (corresponding to 0.36 allyl alcohol molecules per surface Pd atom). Table 3 summarizes the observed IR vibration frequencies for allyl alcohol at low and at high coverages in comparison to previous studies found in literature.

3.3.1. Unperturbed allyl alcohol molecule in multilayer. At high allyl alcohol coverages, $\mathrm{C}-\mathrm{H}$ stretching vibrations are detected at $3260 \mathrm{~cm}^{-1}, 3092 \mathrm{~cm}^{-1}, 3013 \mathrm{~cm}^{-1}, 2989 \mathrm{~cm}^{-1}$, $2920 \mathrm{~cm}^{-1}$, and in the range of $2870-2850 \mathrm{~cm}^{-1}$. The very broad and intense IR absorption near $3260 \mathrm{~cm}^{-1}$ is related to $\mathrm{O}-\mathrm{H}$ stretching in hydrogen bonded $\mathrm{OH}$ groups. In previous publications, this vibration was reported near $3300 \mathrm{~cm}^{-1} \cdot{ }^{12,43}$ The $\mathrm{CH}_{2}$ asymmetric and symmetric stretching vibrations are assigned to peaks at $2920 \mathrm{~cm}^{-1}$ and $2870-2850 \mathrm{~cm}^{-1}$. In previous studies on allyl alcohol in rare gas solutions and in the gas phase, the asymmetric stretching was observed at 2967$2903 \mathrm{~cm}^{-1}$ and the symmetric stretching at $2880-2851 \mathrm{~cm}^{-1} \cdot{ }^{26,27}$ The peak at $3092 \mathrm{~cm}^{-1}$ is assigned to the asymmetric stretching of the vinyl- $\mathrm{CH}_{2}$ group and the vibrational modes at $3013 \mathrm{~cm}^{-1}$, and $2989 \mathrm{~cm}^{-1}$ are related to vinyl- $\mathrm{CH}_{2}$ symmetric stretching and $\mathrm{CH}$ stretching modes. Previously, the vinyl- $\mathrm{CH}_{2}$ asymmetric stretching was observed at $3124-3086 \mathrm{~cm}^{-1} \cdot{ }^{26,27}$ The vinyl- $\mathrm{CH}_{2}$ symmetric stretching was found at $3034-2992 \mathrm{~cm}^{-1}$ and the $\mathrm{CH}$ stretching at 3033-3011 $\mathrm{cm}^{-1}$. Hence, the literature values are in good agreement with the vibrational frequencies observed in our study.

The $\mathrm{C}=\mathrm{C}$ stretching vibration can only be observed at high coverage. It appears at $1648 \mathrm{~cm}^{-1}$ and thus $30 \mathrm{~cm}^{-1}$ higher as compared to acrolein. In previous studies on allyl alcohol, the $\mathrm{C}=\mathrm{C}$ stretching vibration was reported at $1655-1644 \mathrm{~cm}^{-1} \cdot{ }^{26,27}$
Table 3 Assignment of IR vibrations of allyl alcohol on $\mathrm{Pd}(111)$ at $120 \mathrm{~K}$

\begin{tabular}{|c|c|c|c|}
\hline \multirow[b]{2}{*}{ Mode } & \multicolumn{2}{|c|}{ IR frequency $/ \mathrm{cm}^{-1}$} & \multirow[b]{2}{*}{ Ref./cm ${ }^{-1}$} \\
\hline & Low coverage & High coverage & \\
\hline$\nu(\mathrm{O}-\mathrm{H} \cdots \mathrm{O})$ & & 3260 & $3300^{12,43}$ \\
\hline$\nu_{\mathrm{a}}\left(=\mathrm{CH}_{2}\right)$ & & 3092 & $\begin{array}{l}3124-3099,{ }^{27} \\
3102-3086^{26}\end{array}$ \\
\hline$\nu_{\mathrm{s}}\left(=\mathrm{CH}_{2}\right)$ & & 3013 & $\begin{array}{l}3034-3010^{27} \\
2996-2992^{26}\end{array}$ \\
\hline$\nu(\mathrm{C}-\mathrm{H})$ & & 2989 & $\begin{array}{l}3033-3011^{27} \\
3022^{26}\end{array}$ \\
\hline$\nu_{\mathrm{a}}\left(\mathrm{CH}_{2}\right)$ & $(2897,2877)$ & 2920 & $\begin{array}{l}2967-2903^{27} \\
2948-2934^{26}\end{array}$ \\
\hline$\nu_{\mathrm{s}}\left(\mathrm{CH}_{2}\right)$ & $(2842)$ & $2850-2870$ & $\begin{array}{l}2878-2851^{27} \\
2880-2854^{26}\end{array}$ \\
\hline$\nu(\mathrm{C}=\mathrm{C})$ & & 1648 & $\begin{array}{l}1655-1644^{27} \\
1655^{26}\end{array}$ \\
\hline$\delta\left(\mathrm{CH}_{2}\right)$ & & 1470-1495 & $\begin{array}{l}1500-1482^{27} \\
1463-1453^{26}\end{array}$ \\
\hline$\delta\left(=\mathrm{CH}_{2}\right)$ & & $1406-1450$ & $\begin{array}{l}1429-1410^{26} \\
1440-1399^{27}\end{array}$ \\
\hline $\begin{array}{l}\delta\left(=\mathrm{CH}_{2}\right)^{a} \\
\delta(=\mathrm{CH}\end{array}$ & & $\begin{array}{l}1450 \\
1424\end{array}$ & $\begin{array}{l}1440^{27} \\
1426^{27}\end{array}$ \\
\hline$\delta\left(=\mathrm{CH}_{2}\right)^{c, d}$ & & $\begin{array}{l}1424 \\
1406\end{array}$ & $1399,1409^{27}$ \\
\hline$\omega\left(\mathrm{CH}_{2}\right)$ & & & $\begin{array}{l}1399-1317^{27} \\
1384-1372^{26}\end{array}$ \\
\hline$\delta(\mathrm{O}-\mathrm{H})$ & & $1373-1235$ & $\begin{array}{l}1372-1202,{ }^{27} \\
1328-1321^{26}\end{array}$ \\
\hline$\delta(\mathrm{C}-\mathrm{H})$ & & & $1281-1272^{27}$ \\
\hline$\nu(\mathrm{C}-\mathrm{O})$ & & 1113 & $\begin{array}{l}1111-1033^{27} \\
1110^{26}\end{array}$ \\
\hline$\omega_{\mathrm{T}}\left(\mathrm{HC}=\mathrm{CH}_{2}\right)$ & & 1000 & $\begin{array}{l}1018-841^{15} \\
1020-950^{16} \\
1022-1002^{17} \\
993^{13} \\
995-985^{12} \\
1054-988^{27} \\
1002-995^{26}\end{array}$ \\
\hline
\end{tabular}

$\nu=$ stretching, $\nu_{\mathrm{a}}=$ asymmetric stretching, $\nu_{\mathrm{s}}=$ symmetric stretching $\delta=$ bending, $\omega=$ wagging, $\omega_{\mathrm{T}}=$ trans-wag vibration. ${ }^{a}$ gauche-trans. ${ }^{b}$ gauche-gauche. ${ }^{c}$ cis-trans. ${ }^{d}$ cis-gauche.

In the region below $1500 \mathrm{~cm}^{-1}$, IR absorption is found in the ranges of 1470-1495 $\mathrm{cm}^{-1}, 1406-1450 \mathrm{~cm}^{-1}$, and 1373-1235 $\mathrm{cm}^{-1}$,

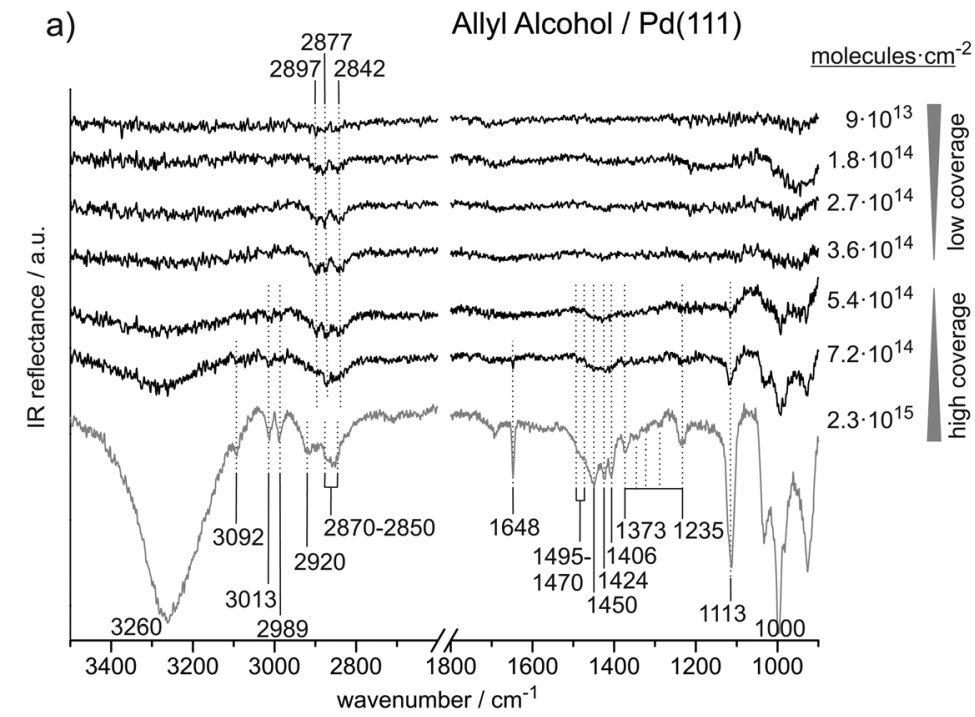

b) TPD after adsorption of $2.3 \cdot 10^{15}$ allyl alcohol $/ \mathrm{cm}^{2}$

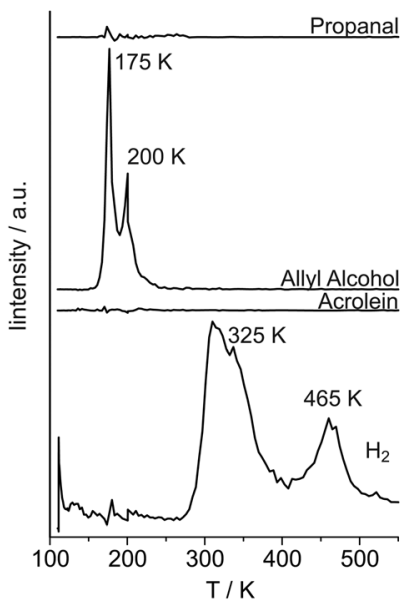

Fig. 3 (a) Coverage-dependent IR spectra of allyl alcohol on Pd(111) recorded at $120 \mathrm{~K}$. (b) TPD after deposition of about six layers of allyl alcohol on Pd(111). 
at $1113 \mathrm{~cm}^{-1}$ and $1000 \mathrm{~cm}^{-1}$. The features from $1495 \mathrm{~cm}^{-1}$ to $1406 \mathrm{~cm}^{-1}$ are assigned to $\mathrm{CH}_{2}$ scissor vibrations. We relate the higher frequencies at $1470-1495 \mathrm{~cm}^{-1}$ to the alkyl- $\mathrm{CH}_{2}$ group, while we assign the lower frequencies from $1406-1450 \mathrm{~cm}^{-1}$ to the vinyl- $\mathrm{CH}_{2}$ group. In literature, scissor deformations of the alkyl$\mathrm{CH}_{2}$ group were found at $1500-1453 \mathrm{~cm}^{-1}$ and of the vinyl- $\mathrm{CH}_{2}$ group at 1440-1399 $\mathrm{cm}^{-1} \cdot{ }^{26,27}$ Durig et al. predicted theoretically that the vinyl- $\mathrm{CH}_{2}$ scissor frequency should strongly depend on the molecular conformation. ${ }^{27}$ According to their results, we tentatively assign the vibration at $1406 \mathrm{~cm}^{-1}$ to the cis-trans and cis-gauche conformer, the absorptions at $1424 \mathrm{~cm}^{-1}$ to the gauche-gauche and the vibration at $1450 \mathrm{~cm}^{-1}$ to the gauche-trans species. Multiple IR adsorption features are observed between $1373 \mathrm{~cm}^{-1}$ and $1235 \mathrm{~cm}^{-1}$, which we assign to $\mathrm{CH}_{2}$ wag as well as $=\mathrm{C}-\mathrm{H}$ and $\mathrm{O}-\mathrm{H}$ bend vibrations. In previous studies, the exact vibration frequencies were found to depend on the conformation of the molecule. ${ }^{27}$ The pronounced vibration at $1113 \mathrm{~cm}^{-1}$ is related to $\mathrm{C}-\mathrm{O}$ stretching vibration, which was reported in literature between $1033 \mathrm{~cm}^{-1}$ and $1111 \mathrm{~cm}^{-1} \cdot{ }^{26,27}$ The very strong IR absorption near $1000 \mathrm{~cm}^{-1}$ is assigned to the $\mathrm{CH}=\mathrm{CH}_{2}$ trans-wag vibration, which is discussed in more detail for acrolein.

3.3.2. Allyl alcohol at low coverage. In the low coverage regime, only a small number of IR absorption features in the $\mathrm{C}-\mathrm{H}$ stretching region are detected. Weak IR vibration features are observed near $2897 \mathrm{~cm}^{-1}, 2877 \mathrm{~cm}^{-1}$, and $2842 \mathrm{~cm}^{-1}$. We tentatively assign the two higher wavenumber peaks to $\mathrm{CH}_{2}$ asymmetric stretching modes of two different allyl alcohol species and the lower frequency vibration to a $\mathrm{CH}_{2}$ symmetric stretching vibration. No vibrations are seen in the frequency range related to $\mathrm{C}=\mathrm{C}$ stretching or $\mathrm{CH}_{x}$ deformation vibrations.

3.3.3. TPD of allyl alcohol. Fig. $3 \mathrm{~b}$ shows the result of a TPD experiment of $2.3 \times 10^{15}$ allyl alcohol molecules $\mathrm{cm}^{-2}$ on $\operatorname{Pd}(111)$, which corresponds to the highest coverage studied by IRAS. Desorption of allyl alcohol, propanal, acrolein, and hydrogen was followed. Allyl alcohol desorbs in two peaks at $175 \mathrm{~K}$ and $200 \mathrm{~K}$, neither propanal nor acrolein desorption were observed. Similar to our studies on propanal and acrolein, a significant amount $\mathrm{H}_{2}$ appears in the gas-phase in two peaks at $325 \mathrm{~K}$ and near $465 \mathrm{~K}$.

\section{Discussion}

\subsection{Acrolein on $\operatorname{Pd}(111)$}

The coverage-dependent IRAS studies show strong changes in characteristic IR vibration frequencies, especially of the $\mathrm{C}=\mathrm{O}$ stretching, $\mathrm{CH}_{2}$ scissor, and $\mathrm{HC}=\mathrm{CH}_{2}$ trans-wag vibrational modes. These changes point strongly to changes in acrolein adsorption geometry with coverage. Below the coverage of $3.6 \times 10^{14}$ molecules per $\mathrm{cm}^{2}$, acrolein forms a sub-monolayer, showing strong deviation in the vibrational spectrum as compared to unperturbed acrolein molecules in a multilayer; the corresponding species are indicated as species A and B in Table 1. Note that the discrimination between $\mathrm{A}$ and $\mathrm{B}$ is tentative and is rather related to different adsorption geometries than to different chemical nature of the adsorbates. Near the coverage of $3.6 \times 10^{14}$ molecules per $\mathrm{cm}^{2}$, which corresponds approximately to accumulation of one acrolein molecule per four Pd surface atoms, acrolein forms a monolayer (species $\mathrm{C}$ in the Table 1), which is characterized by considerably smaller changes of the vibrational spectrum as compared to acrolein ice.

At low acrolein coverages (species A and B), weak IR absorption of $\mathrm{CH}_{2}$ deformation modes was detected. However, no vibrational bands corresponding to $\mathrm{C}=\mathrm{O}, \mathrm{C}=\mathrm{C}$, or $\mathrm{C}-\mathrm{C}$ bonds and no $\mathrm{IR}$ absorption in the range of $\mathrm{C}-\mathrm{H}$ stretching vibrations were observed. This distribution of vibrational bands is in sharp contrast to the spectra of unperturbed molecules in acrolein ice (acrolein type D in Table 1). Particularly the absence of the otherwise very intense $\mathrm{C}=\mathrm{O}$ vibrational band strongly indicates that this band is either strongly perturbed via interaction with Pd or cannot be detected by IRAS due to the metal surface selection rule (MSSR). ${ }^{29-31}$ This latter rule allows only vibrations having a component of the dipole moment perpendicular to the metal substrate. Thus, if the $\mathrm{C}=\mathrm{O}$ bond in acrolein lies flat on the surface at the low acrolein coverages, it would be invisible in IRAS. Both possible reasons - strong perturbation of the $\mathrm{C}=\mathrm{O}$ bond (e.g. via formation of di-sigma complex) as well as the vanishing of the band intensity due to MMSR imply that this bond is parallel to the surface. The same reasons can be put forward in order to explain the missing vibrational bands if the $\mathrm{C}=\mathrm{C}, \mathrm{C}-\mathrm{C}$ and $\mathrm{C}-\mathrm{H}$ stretching regions. It is, however, quite unlikely that all this bands are invisible due to strong perturbation via interaction with the Pd substrate, as this scenario would result in very strained surface species. Instead, the vanishing of this band due to flat lying adsorption geometry of acrolein seems to be more feasible in this case. It should be noted that decomposition of acrolein to form $\mathrm{CO}$ can be excluded based on our spectra. Acrolein decarbonylation would result in accumulation of $\mathrm{CO}$ molecules on the surface, which have a very large dipole moment and should be clearly visible.

It should be noted that MMSR is not a universal rule as in strongly interacting systems even the bands lying parallel to the surface might become visible in IRAS due to surface electron density being "pumped" in and out of the metal surface thus producing a strong dynamic dipole moment perpendicular to the surface. However, this scenario does not apply in our case to $\mathrm{C}=\mathrm{C}$ and $\mathrm{C}=\mathrm{O}$ bonds of acrolein, as these vibrations are not seen at low coverage and therefore the electron density pumping into the parallel lying bands can be safely excluded.

At increasing acrolein coverages, changes in the $\mathrm{CH}_{2}$ scissor vibration frequency were detected. While it was significantly shifted with respect to acrolein ice by $25 \mathrm{~cm}^{-1}$ in the lowest coverage limit (species A, $1400 \mathrm{~cm}^{-1}$ ), the frequency changes to the value of $1425 \mathrm{~cm}^{-1}$ characteristic for an unperturbed molecules. We tentatively refer these changes to the formation of the species $\mathrm{B}$. The different $\mathrm{CH}_{2}$ scissor vibration frequencies of species A and B are rather related to a different strength and/or degree of perturbation of the corresponding group upon interaction with $\mathrm{Pd}$. The unperturbed vibration of the $\mathrm{CH}_{2}$ group in species B points to a weaker interaction of this group with the surface, which might arise e.g. from a more upright orientation of this group and, consequently, larger distance between the $\mathrm{CH}_{2}$-entity and $\mathrm{Pd}$ surface. Interestingly, the $\mathrm{C}=\mathrm{O}$ 
band remains still invisible in IRAS of these species suggesting that the $\mathrm{CH}_{2}$ groups tilts at lower coverages than the $\mathrm{C}=\mathrm{O}$ group. A very similar scenario was observed for the coveragedependent changes of a similar $\alpha, \beta$-unsaturated ketone isophorone, whose changes in the adsorption geometry were followed by combination of IRAS and NEXAFS. ${ }^{41,44}$ For this molecule, we also found that the initial flat adsorption geometry changes to an upright geometry with increasing coverage, but the $\mathrm{C}=\mathrm{C}$ bond acquires the tilted geometry at lower coverages than the $\mathrm{C}=\mathrm{O}$ bond, which is accompanied by a strong perturbation of both geometrical and electronic structure of this molecule.

It should be noted that the IR absorption features of the sub-monolayer species are very weak and a clear identification of the molecular structure of the adsorbates is hardly possible. Hence, the most reliable information obtained by the IR studies at sub-monolayer coverages may rather be related to the adsorbates' geometry than to their exact molecular structure. The absence of the $\mathrm{C}=\mathrm{O}, \mathrm{C}=\mathrm{C}$, and $\mathrm{C}-\mathrm{C}$ bond stretching vibration signals reveals a flat-lying molecular plane on the $\operatorname{Pd(111)~surface.~}$

At the exposure $3.6 \times 10^{14}$ acrolein molecules per $\mathrm{cm}^{2}$, a clearly detectable $\mathrm{C}=\mathrm{O}$ stretching vibration appears in the spectrum at $1663 \mathrm{~cm}^{-1}$. This observation indicates that the $\mathrm{C}=\mathrm{O}$ bond acquires more upright configuration with respect to the surface plane. The frequency is shifted by $17 \mathrm{~cm}^{-1}$ as compared to the unperturbed molecule in acrolein ice, pointing to a weakening of the $\mathrm{C}=\mathrm{O}$ bond due to a strong interaction with the metal surface. Note that species $\mathrm{C}$ related to the monolayer coverage can be only observed in a very narrow coverage range close to one acrolein molecule per four Pd surface atoms. TPD spectra obtained for the monolayer coverage show complete decomposition of the entire acrolein overlayer indicating that the whole layer is strongly interacting with the surface. Previous DFT calculations show that acrolein may adsorb on a $\operatorname{Pd}(111)$ surface in an $\eta_{4}$ mode, in which it would block four Pd atoms. ${ }^{2}$ This theoretical prediction is in good agreement with our experimental data suggesting that adsorption of one acrolein molecule per four Pd surface atoms results in formation of a homogeneously distributed and strongly bonded monolayer of flat-lying molecules.

Finally, at the highest investigated coverages, acrolein adsorbs in a multilayer (species D). The corresponding IR vibrational bands appear at frequencies similar to that reported in literature for gas-phase acrolein. Therefore, the IR spectrum of species D provides a good reference for vibrations of mainly unperturbed adsorbed molecules.

\subsection{Propanal on $\operatorname{Pd}(111)$}

The vibration frequencies of propanal exhibit a very strong coverage dependence, which gives some insight into the adsorbate structures formed on $\operatorname{Pd}(111)$. Similar to acrolein, we observe the transition from the sub-monolayer to multilayer adsorption regime in the range from $3.6 \times 10^{14}$ to $5.4 \times 10^{14}$ molecules per $\mathrm{cm}^{2}$. It is particularly interesting to compare the vibrational signatures of adsorbed acrolein and propanal species as they differ only in the presence of the conjugated $\pi$ system in acrolein.
Already at sub-monolayer coverages, propanal exhibits a number of IR vibrational modes. A variety of $\mathrm{CH}_{3}, \mathrm{CH}_{2}, \mathrm{CH}$, $\mathrm{C}-\mathrm{C}-\mathrm{C}$, as well as $\mathrm{C}=\mathrm{O}$ vibration have been identified at low propanal coverages. While all vibrational modes of the $\mathrm{CH}_{2}$ group appear at identical frequencies as for unperturbed molecules at multilayer coverages, the $\mathrm{CH}_{3}$ stretching vibrations are significantly affected by the Pd surface at sub-monolayer coverages. $\mathrm{CH}_{3}$ asymmetric and symmetric stretching vibrations have been observed at $2960 \mathrm{~cm}^{-1}$ and $2876 \mathrm{~cm}^{-1}$ and thus $27 \mathrm{~cm}^{-1}$ and $8 \mathrm{~cm}^{-1}$ lower than in the unperturbed species relative to the multilayer. The $\mathrm{CH}_{3}$ symmetric bending and $\mathrm{CH}_{3}$ rocking vibrations appear near $1360 \mathrm{~cm}^{-1}$ and $1070 \mathrm{~cm}^{-1}$, respectively, which is approximately $30 \mathrm{~cm}^{-1}$ lower than in multilayer species. However, the most drastic changes have been observed for the stretching vibration frequency of the $\mathrm{C}=\mathrm{O}$ group as a function of increasing coverage.

On the one hand, the pronounced coverage-dependent changes of the $\mathrm{C}=\mathrm{O}$ stretching vibration frequency can be indicative of a strong interaction of this group with the metal surface. In particular, close to the monolayer coverage, three vibrational bands on the $\mathrm{C}=\mathrm{O}$ vibrational were observed: at $1663 \mathrm{~cm}^{-1}$, at $1695 \mathrm{~cm}^{-1}$ and at $1728 \mathrm{~cm}^{-1}$. While the first band at $1663 \mathrm{~cm}^{-1}$ appears and quickly saturates in the submonolayer regime, the second band at $1695 \mathrm{~cm}^{-1}$ grows in intensity up the coverage of $c a .5 .4 \times 10^{14}$ propanal molecules per $\mathrm{cm}^{2}$. The third band at $1728 \mathrm{~cm}^{-1}$ continuously grows in intensity with increasing coverage and represents one of the major vibrational features in propanal ice. The vibrational band at $1663 \mathrm{~cm}^{-1}$ is most likely related to surface species formed at sub-monolayer coverages or close to monolayer and points to a major weakening of the $\mathrm{C}=\mathrm{O}$ bond in coverage range due to strong interaction of propanal with $\operatorname{Pd}(111)$ and/or strong perturbation of its electronic structure. High intensity of the $\mathrm{C}=\mathrm{O}$ bond near the full monolayer coverage indicates a rather upright orientation of this bond on $\operatorname{Pd}(111)$. This observation is in contrast to acrolein, which was found to adsorb in a flat-lying adsorption geometry with both $\mathrm{C}=\mathrm{C}$ and $\mathrm{C}=\mathrm{O}$ binds being nearly parallel to the surface even at the smallest investigated coverages. The second $\mathrm{C}=\mathrm{O}$ vibrational band $\left(1695 \mathrm{~cm}^{-1}\right)$ is rather indicative of formation of the second propanal layer, which is less perturbed by the interaction with Pd and therefore exhibits the $\mathrm{C}=\mathrm{O}$ vibrational frequency lying very closer to the gas phase and ice value $\left(1728 \mathrm{~cm}^{-1}\right)$. The appearance of the vibrational band at 1728 at $5.4 \times 10^{14}$ molecules per $\mathrm{cm}^{2}$ indicates the onset of propanal ice formation. As the frequency does not change in the next layers, it can be safely assumed that a noticeable perturbation of the electronic structure of propanal is possible only for molecules in the first two adsorption layers.

Significant differences between acrolein and propanal were observed in the region of the $\mathrm{C}-\mathrm{H}$ stretching vibrations. While these vibrations cannot be seen at sub-monolayer coverages of acrolein, these modes are clearly visible already at the lowest coverage of propanal. This observation indicates a different ordering of the $\mathrm{CH}_{x}$ groups of propanal and acrolein on the $\mathrm{Pd}$ surface. In acrolein, the dynamic dipole moment of these vibrations must be close to parallel to the metal surface in 
order to become invisible in IRAS due to MSSR, while the same vibrations in propanal obviously exhibit rather large perpendicular component of the dipole moment. This observation is consistent with the more upright adsorption geometry of propanal discussed above, resulting in the $\mathrm{C}=\mathrm{O}$ vibrational peaks of high intensity observed already at close to monolayer coverages.

It is important to note that in the high coverage regime the C-H stretching vibrations of propanal appear at significantly higher wavenumbers compared to acrolein $\left(2752-2987 \mathrm{~cm}^{-1}\right.$ for propanal and $2705-2857 \mathrm{~cm}^{-1}$ for acrolein). These differences result most likely from the different chemical environment of the $\mathrm{CH}_{x}$ species in acrolein vs. propanal, i.e. from the presence or absence of the conjugated $\pi$-system of double bonds. For instance, vibrations of the aldehyde- $\mathrm{C}-\mathrm{H}$ groups in acrolein gives rise to peaks at $2705 \mathrm{~cm}^{-1}$ and $2766 \mathrm{~cm}^{-1}$, while the same modes in propanal are observed at $2752 \mathrm{~cm}^{-1}$ and $2868 \mathrm{~cm}^{-1}$. The $\mathrm{CH}_{2}$ stretching vibrations in propanal appear at $2943 \mathrm{~cm}^{-1}$ and $2904 \mathrm{~cm}^{-1}$ and thus at significantly higher wavenumbers as the $=\mathrm{CH}_{2}$ vibration in acrolein at $2857 \mathrm{~cm}^{-1}$ and $2820 \mathrm{~cm}^{-1}$, which involve a $\mathrm{C}$ atom at an unsaturated $\mathrm{C}=\mathrm{C}$ bond.

It should be pointed out that the differences in the intensities as well as in the frequencies of the $\mathrm{C}-\mathrm{H}$ stretching vibrations can allow an independent in situ monitoring of adsorbed acrolein and its hydrogenation product propanal under the reaction conditions of acrolein hydrogenation.

The different propanal surface species formed on Pd in the coverage rage $3.6 \times 10^{14}$ to $5.4 \times 10^{14}$ molecules per $\mathrm{cm}^{2}$, can be clearly correlated to the temperature-programmed desorption experiments. TPD experiments of propanal starting from the multilayer coverage show desorption of intact propanal in multilayer at $145 \mathrm{~K}$ and monolayer at $180 \mathrm{~K}$. Hydrogen desorption peaks are observed at $345 \mathrm{~K}$ and $470 \mathrm{~K}$. This desorption pattern indicates that not the entire overlayer of propanal decomposes to produce hydrogen and some fraction of propanal can desorb as an intact molecule. The species with the lower desorption temperature of $145 \mathrm{~K}$ is related to the weakly bound propanal characterized by the mostly unperturbed $\mathrm{C}=\mathrm{O}$ vibration at $1728 \mathrm{~cm}^{-1}$. The propanal species desorbing at $180 \mathrm{~K}$ is most likely related to the propanal adsorbed in the second layer and characterized by the $\mathrm{C}=\mathrm{O}$ vibrational frequency of $1693 \mathrm{~cm}^{-1}$ maybe with some fraction of propanal adsorbed in the first monolayer with the $\mathrm{C}=\mathrm{O}$ stretching frequency of $1663 \mathrm{~cm}^{-1}$. It is also very likely that the sub-monolayer type of species $(\mathrm{C}=\mathrm{O}$ stretching frequency of $1663 \mathrm{~cm}^{-1}$ ) undergo partial decomposition in a TPD run resulting in hydrogen desorption.

\subsection{Allyl alcohol on $\operatorname{Pd}(111)$}

At low coverages (up to $3.6 \times 10^{14}$ molecules per $\mathrm{cm}^{2}$ ) of allyl alcohol on Pd(111), only weak IR absorption features related to $\mathrm{C}-\mathrm{H}$ stretching vibrations were detected. The absence of the otherwise strong vibrational bands in the range of $\mathrm{C}-\mathrm{O}$ and $\mathrm{O}-\mathrm{H}$ frequencies (near $1110 \mathrm{~cm}^{-1}$ and $3260 \mathrm{~cm}^{-1}$, respectively) point to a flat lying adsorption geometry of allyl alcohol at sub-monolayer coverages. This adsorption geometry is additionally corroborated by the fact that some low intensity bands in the range of the $\mathrm{CH}_{2}$ stretching vibrations $\left(2840-2900 \mathrm{~cm}^{-1}\right)$ can be observed even at sub-monolayer coverages. These bands have small dipole moments, which normally results in the low intensity of these bands as compared to the $\mathrm{C}-\mathrm{O}$ and $\mathrm{O}-\mathrm{H}$ vibrations possessing large dipole moments. The fact that these low intensity bands are present and their frequency correspond well to the frequencies in allyl alcohol ice mean that the molecules are adsorbed on the surface and are most likely intact; however, their $\mathrm{C}-\mathrm{O}$ and $\mathrm{O}-\mathrm{H}$ vibrational bands are not visible due to flat lying adsorption geometry.

At allyl alcohol coverages higher than $3.6 \times 10^{14}$ molecules per $\mathrm{cm}^{2}$, a transition from sub-monolayer coverage to a monoand multilayer coverages is observed. This transitions is characterized by evolution of a large number of bands characteristic for the $\mathrm{O}-\mathrm{H}, \mathrm{CH}_{x}, \mathrm{C}-\mathrm{O}$, and $\mathrm{C}=\mathrm{C}$ groups at the frequencies nearly identical to those reported in previous studies on unperturbed allyl alcohol molecules in the gas phase and rare gas solutions. Appearance of these vibrational bands clearly indicates the change of the adsorption geometry from the flat lying to a more tilted geometry at higher coverages. Finally, these vibrational bands merely grow in intensity without undergoing any significant shifts, which indicates the growth of an allyl alcohol multilayer. In the multilayer regime, all recorded vibrational frequencies are in good agreement with the literature values reported earlier. This observation suggests a transition from the monolayer to multilayer regime in the range of $3.6 \times 10^{14}$ to $5.4 \times 10^{14}$ allyl alcohol molecules per $\mathrm{cm}^{2}$ and thus approximately at the same surface coverage as determined for acrolein and propanal.

TPD studies on multilayers of allyl alcohol on $\operatorname{Pd}(111)$ show desorption of intact allyl alcohol at $175 \mathrm{~K}$ and $200 \mathrm{~K}$ and hydrogen at $325 \mathrm{~K}$ and $465 \mathrm{~K}$. Desorption of allyl alcohol at $175 \mathrm{~K}$ is clearly related to multilayer regime, while the peak at $200 \mathrm{~K}$ can be assigned to desorption from the monolayer. It is interesting to note that a fraction of the allyl alcohol might desorb intact from the monolayer, while the rest of the monolayer successively decomposes resulting in hydrogen desorption peaks at $325 \mathrm{~K}$ and $465 \mathrm{~K}$. Interestingly, the hightemperature $\mathrm{H}_{2}$ desorption in propanal and allyl alcohol TPD experiments appears approximately at the same temperature. This observation indicates that the hydrocarbon fragments remaining on the surface up to $470 \mathrm{~K}$ might be identical for both molecules propanal and allyl alcohol. This temperature range was previously reported to be characteristic of decomposition of the $\mathrm{CH}_{x}$ groups. ${ }^{35}$ The low temperature $\mathrm{H}_{2}$ peak observed in allyl alcohol decomposition, is by about $20 \mathrm{~K}$ lower than that one recorded for propanal. This difference is most likely related to the lower stability of the hydrogen atoms attached to the $\mathrm{C}=\mathrm{C}$ bond in allyl alcohol. In agreement with this hypothesis, the low-temperature $\mathrm{H}_{2}$ peak observed in acrolein decomposition (the onset at $315 \mathrm{~K}$ ) lies much closer to the corresponding peak of allyl alcohol $(320 \mathrm{~K})$ than of propanal $(340 \mathrm{~K})$. It might be concluded from these observations that the molecules containing $\mathrm{C}=\mathrm{C}$ bonds are more prone to decompose as compared to their saturated counterparts.

The desorption of allyl alcohol from Pd(111) occurs at $175 \mathrm{~K}$ and $200 \mathrm{~K}$, compared to the desorption temperature of propanal at $145 \mathrm{~K}$ and $180 \mathrm{~K}$. Redhead analysis of the desorption curves ${ }^{45}$ results in the estimated binding energies of $50 \mathrm{~kJ} \mathrm{~mol}^{-1}$ and 
$44 \mathrm{~kJ} \mathrm{~mol}^{-1}$ for the mono- and multi-layer allyl alcohol species and $45 \mathrm{~kJ} \mathrm{~mol}^{-1}$ and $36 \mathrm{~kJ} \mathrm{~mol}^{-1}$ for the two propanal species. This difference in the binding energies of two potential products of acrolein hydrogenation might play an important role for the overall hydrogenation process as propanal is expected to desorb faster than allyl alcohol at a given temperature.

It is interesting to note that in sub-monolayer coverage regime acrolein and allyl alcohol adopt a flat-lying adsorption geometry on the $\operatorname{Pd}(111)$ surface, while propanal is strongly inclined with respect to $\operatorname{Pd}(111)$ surface plane, interacting with the surface primarily through the $\mathrm{C}=\mathrm{O}$ group. This result is in good agreement with our previous study on the adsorption geometries of an unsaturated $\alpha, \beta$-ketone isophorone and its saturated counterpart - trimethylcyclohexanone. By using a combination of IRAS and NEXAFS, we were able to show that isophorone adopts a flat-lying adsorption geometry on $\operatorname{Pd}(111)$ at sub-monolayer coverages, while $\mathrm{TMCH}$ is attached to the surface via the $\mathrm{C}=\mathrm{O}$ bond and is strongly tilted. ${ }^{41}$ It might be speculated that the presence of the $\mathrm{C}=\mathrm{C}$ bond plays an important role in determining the adsorption geometry of surface species and, as a result, could explain the selectivity of $\mathrm{C}=\mathrm{C}$ vs. $\mathrm{C}=\mathrm{O}$ bond hydrogenation in $\alpha, \beta$-unsaturated aldehydes. Further theoretical calculations are needed in order to understand this issue. The strong changes of the adsorbates structure from the unsaturated to the saturated aldehyde is expected to play a crucial role in explaining the selectivity of $\mathrm{C}=\mathrm{C} v s$. $\mathrm{C}=\mathrm{O}$ bond hydrogenation in $\alpha, \beta$-unsaturated aldehydes.

\section{Conclusions}

Adsorption of acrolein, propanal and allyl alcohol on $\operatorname{Pd}(111)$ was investigated in this study by a combination of infrared reflection absorption spectroscopy and temperature programmed desorption. The evolution of IR vibrational bands measured as a detailed function of adsorbates coverage in the broad range starting from sub-monolayer up to multilayer coverages provides deep insights into the adsorbate structures formed on $\operatorname{Pd}(111)$. For all three compounds, we have found mostly unperturbed molecular structures in the multilayer regime and observed strong perturbation of the molecules upon interaction with Pd. A transition from the sub-monolayer to the multilayer regime has been observed in the range from $3.6 \times 10^{14}$ to $5.4 \times 10^{14}$ molecules per $\mathrm{cm}^{2}$ for all three compounds.

For adsorption of acrolein in the sub-monolayer regime, two types of surface species (A and B in Table 1) were spectroscopically identified that adsorb with $\mathrm{C}=\mathrm{O}, \mathrm{C}=\mathrm{C}$ and $\mathrm{C}-\mathrm{C}$ bonds parallel to the metal surface. Remarkably, only deformation vibrations involving the $=\mathrm{CH}_{2}$ group have been observed at the lowest acrolein coverages. In contrast, at a coverage close to a monolayer (give the number of molecules) a more upright orientation of the $\mathrm{C}=\mathrm{O}$ bond was observed. The corresponding vibrational frequency was found to be strongly red-shifted from the gas phase and acrolein ice value, indicating a significant weakening of the $\mathrm{C}=\mathrm{O}$ bond in acrolein by the interaction with Pd and strong distortion of the conjugated $\pi$ system. At higher coverages, the mainly unperturbed acrolein species is formed with the vibrational frequencies in good agreement with the previously reported values for gas phase acrolein.

Three coverage regimes were identified in the IRAS experiments on propanal adsorption, which can be tentatively assigned to formation of the first and second propanal layer as well as building up the propanal multilayer. In the sub-/monolayer regime, the $\mathrm{C}=\mathrm{O}$ vibrational band $\left(1663 \mathrm{~cm}^{-1}\right)$ was observed to strongly interact with $\mathrm{Pd}$, resulting in a strong shift to lower wavenumbers as compared to unperturbed molecules. High intensity of this band as well as $\mathrm{C}-\mathrm{H}$ stretching vibrations points to a strong inclination of adsorbed propanal molecules with respect to the Pd surface even at sub-monolayer coverages. Close to the monolayer coverage (give the number of molecules), the onset of a second $\mathrm{C}=\mathrm{O}$ vibrational band at higher frequencies $\left(1693 \mathrm{~cm}^{-1}\right)$ is observed that grows in intensity with increasing coverage and later saturates. We interpret this observation as formation of a second propanal layer characterized by lower binding to the underlying metal substrate and weaker perturbation of the electronic structure. At higher coverages, a multilayer of propanal was formed characterized by essentially non-perturbed IR spectra compared to gas phase propanal.

In the case of allyl alcohol, identification of adsorbates at low coverages is difficult due to weak IR absorption and most likely flat-lying adsorption geometry of allyl alcohol. We were able to identify a few $\mathrm{C}-\mathrm{H}$ vibration features in the low-coverage regime. With increasing coverage, however, a transition to the multilayer regime was detected and a large number of distinct IR vibrational modes were observed with the vibrational frequencies characteristic for unperturbed gas phase molecules.

We found pronounced differences in the adsorbates' structures of acrolein, propanal and allyl alcohol on the $\operatorname{Pd}(111)$ surface. While at sub-monolayer coverages acrolein and allyl alcohol species adsorb with the molecular chain parallel to the surface, propanal adsorbs in a strongly tilted geometry with respect to $\operatorname{Pd}(111)$ surface plane, interacting with the surface primarily through the $\mathrm{C}=\mathrm{O}$ group. This finding might suggest that the presence of the $\mathrm{C}=\mathrm{C}$ bond plays an important role in determining the adsorption geometry of surface species. The strong changes of the adsorbates structure from the unsaturated to the saturated aldehyde is expected to play a crucial role in explaining the selectivity of $\mathrm{C}=\mathrm{C} v s$. $\mathrm{C}=\mathrm{O}$ bond hydrogenation in $\alpha, \beta$-unsaturated aldehydes.

\section{Acknowledgements}

S. S. acknowledges support from the Fonds der Chemischen Industrie for the Chemiedozentenstipendium and the European Research Council (ERC Starting Grant 335205 ENREMOS).

\section{References}

1 P. Claus, Selective hydrogenation of $\alpha, \beta$-unsaturated aldehydes and other $\mathrm{C}=\mathrm{O}$ and $\mathrm{C}=\mathrm{C}$ bonds containing compounds, Top. Catal., 1998, 5, 51-62.

2 F. Delbecq and P. Sautet, Competitive $\mathrm{C}=\mathrm{C}$ and $\mathrm{C}=\mathrm{O}$ adsorption of alpha-beta-unsaturated aldehydes on Pt and 
Pd surfaces in relation with the selectivity of hydrogenation reactions - a theoretical approach, J. Catal., 1995, 152, 217-236.

3 J. C. de Jesus and F. Zaera, Adsorption and thermal chemistry of acrolein and crotonaldehyde on $\mathrm{Pt}(111)$ surfaces, Surf. Sci., 1999, 430, 99-115.

4 K. Brandt, M. E. Chiu, D. J. Watson, M. S. Tikhov and R. M. Lambert, Chemoselective Catalytic Hydrogenation of Acrolein on $\mathrm{Ag}(111)$ : Effect of Molecular Orientation on Reaction Selectivity, J. Am. Chem. Soc., 2009, 131, 17286-17290.

5 H. Wei, C. Gomez, J. Liu, N. Guo, T. Wu, R. Lobo-Lapidus, C. L. Marshall, J. T. Miller and R. J. Meyer, Selective hydrogenation of acrolein on supported silver catalysts: A kinetics study of particle size effects, J. Catal., 2013, 298, 18-26.

6 M. Bron, D. Teschner, A. Knop-Gericke, B. Steinhauer, A. Scheybal, M. Havecker, D. Wang, R. Fodisch, D. Honicke, A. Wootsch, R. Schlogl and P. Claus, Bridging the pressure and materials gap: in-depth characterisation and reaction studies of silver-catalysed acrolein hydrogenation, J. Catal., 2005, 234, 37-47.

7 M. Bron, D. Teschner, A. Knop-Gericke, F. C. Jentoft, J. Krohnert, J. Hohmeyer, C. Volckmar, B. Steinhauer, R. Schlogl and P. Claus, Silver as acrolein hydrogenation catalyst: intricate effects of catalyst nature and reactant partial pressures, Phys. Chem. Chem. Phys., 2007, 9, 3559-3569.

8 P. Gallezot and D. Richard, Selective hydrogenation of alpha,beta-unsaturated aldehydes, Catal. Rev.: Sci. Eng., 1998, 40, 81-126.

9 K.-H. Dostert, C. P. O'Brien, F. Ivars-Barceló, S. Schauermann and H. J. Freund, Spectators Control Selectivity in Surface Chemistry: Acrolein Partial Hydrogenation over Pd, J. Am. Chem. Soc., 2015, 137, 13496-13502.

10 R. A. Karakhanov, T. I. Odintsova, V. B. Yakovlev and A. P. Rodin, Selective catalytic-hydrogenation of doublebonds in unsaturated furan ketones, React. Kinet. Catal. Lett., 1987, 33, 219-221.

11 M. L. A. Vonholleben, M. Zucolotto, C. A. Zini and E. R. Oliveira, A selective reduction of alpha,beta-unsaturated ketones, Tetrahedron, 1994, 50, 973-978.

12 N. B. Colthup, L. H. Daly and S. E. Wiberley, Introduction to Infrared and Raman Spectroscopy, Academic Press, San Diego and London, 3rd edn, 1990.

13 Y. Hamada, Y. Nishimura and M. Tsuboi, Infrared-spectrum of trans-acrolein, Chem. Phys., 1985, 100, 365-375.

14 C. Puzzarini, E. Penocchio, M. Biczysko and V. Barone, Molecular Structure and Spectroscopic Signatures of Acrolein: Theory Meets Experiment, J. Phys. Chem. A, 2014, 118, 6648-6656.

15 S. Fujii, N. Osaka, M. Akita and K. Itoh, Infrared reflectionabsorption spectroscopic study on the adsorption structures of acrolein on an evaporated silver film, J. Phys. Chem., 1995, 99, 6994-7001.

16 M. Akita, N. Osaka and K. Itoh, Infra-red reflection absorption spectroscopic study on adsorption structures of acrolein on polycrystalline gold and $\mathrm{Au}(111)$ surfaces under ultra-high vacuum conditions, Surf. Sci., 1998, 405, 172-181.

17 N. Osaka, M. Akita and K. Itoh, Infrared reflection-absorption spectroscopic study on the adsorption structures of 1,3butadiene at $\mathrm{Au}(111)$ and $\mathrm{Ag}(111)$ surfaces, J. Phys. Chem. $B, 1998,102,6817-6824$.

18 D. Loffreda, Y. Jugnet, F. Delbecq, J. C. Bertolini and P. Sautet, Coverage Dependent Adsorption of Acrolein on Pt(111) from a Combination of First Principle Theory and HREELS Study, J. Phys. Chem. B, 2004, 108, 9085-9093.

19 C. J. Kliewer, M. Bieri and G. A. Somorjai, Hydrogenation of the alpha,beta-Unsaturated Aldehydes Acrolein, Crotonaldehyde, and Prenal over Pt Single Crystals: A Kinetic and Sum-Frequency Generation Vibrational Spectroscopy Study, J. Am. Chem. Soc., 2009, 131, 9958-9966.

20 G. A. Guirgis, B. R. Drew, T. K. Gounev and J. R. Durig, Conformational stability and vibrational assignment of propanal, Spectrochim. Acta, Part A, 1998, 54, 123-143.

21 S. G. Frankiss and W. Kynaston, Vibrational-spectra of propanal, 1-deuteropropanal and 2,2-dideuteropropanal, Spectrochim. Acta, Part A, 1972, A28, 2149-2161.

22 G. Sbrana and V. Schettin, Vibrational spectra and isomerism in propyl-and butylaldehydes, J. Mol. Spectrosc., 1970, 33, 100-108.

23 J. S. Byrne, K. J. Morgan and P. F. Jackson, Carbonyl group frequency. 4. Aliphatic aldehydes, J. Chem. Soc., Perkin Trans. 2, 1972, 1291-1295.

24 S. Pinchas, Infrared absorption of the aldehydic $\mathrm{C}-\mathrm{H}$ group, Anal. Chem., 1955, 27, 2-6.

25 D. F. Eggers and W. E. Lingren, C-H Vibrations in aldehydes, Anal. Chem., 1956, 28, 1328-1329.

26 B. Silvi and J. P. Perchard, Vibration-spectra and normal coordinates of 4 isotopic allyl alcohol species, Spectrochim. Acta, Part A, 1976, 32, 11-22.

27 J. R. Durig, A. Ganguly, A. M. El Defrawy, C. Zheng, H. M. Badawi, W. A. Herrebout, B. J. van der Veken, G. A. Guirgis and T. K. Gounev, Conformational stability of allyl alcohol from temperature dependent infrared spectra of rare gas solutions, ab initio calculations, $r(0)$ structural parameters, and vibrational assignment, J. Mol. Struct., 2009, 922, 114-126.

28 J. M. I. Libuda, J. Hartmann and H. J. Freund, A molecular beam/surface spectroscopy apparatus for the study of reactions on complex model catalysts, Rev. Sci. Instrum., 2000, 71, 4395-4408.

29 F. M. Hoffmann, Infrared reflection-absorption spectroscopy of adsorbed molecules, Surf. Sci. Rep., 1983, 3, 107-192.

30 S. A. Francis and A. H. Ellison, Infrared spectra of monolayers on metal mirrors, J. Opt. Soc. Am., 1959, 49, 131-138.

31 P. Hollins and J. Pritchard, Infrared studies of chemisorbed layers on single crystals, Prog. Surf. Sci., 1985, 19, 275-349.

32 Y. Hamada, Y. Nishimura and M. Tsuboi, Infrared spectrum of trans-acrolein, Chem. Phys., 1985, 100, 365-375.

33 S. E. Stein, NIST Chemistry WebBook, NIST Standard Reference Database Number, 69, ed. P. J. L. a. W. G. Mallard, National Institute of Standards and Technology, Gaithersburg MD, 2014. 
34 F. Zaera, New advances in the use of infrared absorption spectroscopy for the characterization of heterogeneous catalytic reactions, Chem. Soc. Rev., 2014, 43, 7624-7663.

35 W. Liu, A. Savara, X. Ren, W. Ludwig, K.-H. Dostert, S. Schauermann, A. Tkatchenko, H.-J. Freund and M. Scheffler, Toward Low-Temperature Dehydrogenation Catalysis: Isophorone Adsorbed on Pd(111), J. Phys. Chem. Lett., 2012, 3, 582-586.

36 I. Lee and F. Zaera, Thermal Chemistry of C4 Hydrocarbons on Pt(111): Mechanism for Double-Bond Isomerization, J. Phys. Chem. B, 2005, 109, 2745-2753.

37 L. J. Bellamy and R. F. Branch, The infra-red spectra of chelate compounds. Part II. Metal chelate compounds of [small beta]-diketones and of salicylaldehyde, J. Chem. Soc., 1954, 4491-4494.

38 E. Finocchio, G. Busca, V. Lorenzelli and R. J. Willey, FTIR studies on the selective oxidation and combustion of light hydrocarbons at metal oxide surfaces. Propane and propene oxidation on $\mathrm{MgCr}_{2} \mathrm{O}_{4}$, J. Chem. Soc., Faraday Trans., 1994, 90, 3347-3356.

39 L. E. Murillo, A. M. Goda and J. G. Chen, Selective Hydrogenation of the $\mathrm{CO}$ Bond in Acrolein through the Architecture of Bimetallic Surface Structures, J. Am. Chem. Soc., 2007, 129, 7101-7105.
40 J. E. Bailie, C. H. Rochester and G. J. Hutchings, IR study of acrolein hydrogenation over $\mathrm{Co} / \mathrm{SiO}_{2}$ catalysts, J. Chem. Soc., Faraday Trans., 1997, 93, 4389-4394.

41 K.-H. Dostert, C. P. O’Brien, W. Liu, W. Riedel, A. Savara, A. Tkatchenko, S. Schauermann and H.-J. Freund, Adsorption of isophorone and trimethyl-cyclohexanone on $\operatorname{Pd}(111)$ : A combination of infrared reflection absorption spectroscopy and density functional theory studies, Surf. Sci., 2016, DOI: 10.1016/j.susc.2016.01.026.

42 F. M. Hoffmann, Infrared reflection-absorption spectroscopy of adsorbed molecules, Surf. Sci. Rep., 1983, 3, 107-192.

43 A. V. Stuart and G. Sutherland, Effect of hydrogen bonding on the deformation frequencies of the hydroxyl group in alcohols, J. Chem. Phys., 1956, 24, 559-570.

44 K.-H. Dostert, C. P. O’Brien, W. Riedel, A. Savara, W. Liu, M. Oehzelt, A. Tkatchenko and S. Schauermann, Interaction of Isophorone with $\operatorname{Pd}(111)$ : A Combination of Infrared Reflection-Absorption Spectroscopy, Near-Edge X-ray Absorption Fine Structure, and Density Functional Theory Studies, J. Phys. Chem. C, 2014, 118, 27833-27842.

45 P. A. Redhead, Thermal desorption of gases, Vacuum, 1962, 12, 203-211. 